\title{
ORIGINAL ARTICLE Hyperglycemia exacerbates colon cancer malignancy through hexosamine biosynthetic pathway
}

A Vasconcelos-dos-Santos ${ }^{1}$, HFBR Loponte ${ }^{1}$, NR Mantuano ${ }^{1}$, IA Oliveira ${ }^{1}$, IF de Paula ${ }^{2}$, LK Teixeira ${ }^{3}$, JCM de-Freitas-Junior ${ }^{2}$, KC Gondim², N Heise ${ }^{1}$, R Mohana-Borges ${ }^{1}$, JA Morgado-Díaz ${ }^{2}$, WB Dias ${ }^{1}$ and AR Todeschini ${ }^{1}$

Hyperglycemia is a common feature of diabetes mellitus, considered as a risk factor for cancer. However, its direct effects in cancer cell behavior are relatively unexplored. Herein we show that high glucose concentration induces aberrant glycosylation, increased cell proliferation, invasion and tumor progression of colon cancer. By modulating the activity of the rate-limiting enzyme, glutamine-fructose-6-phosphate amidotransferase (GFAT), we demonstrate that hexosamine biosynthetic pathway (HBP) is involved in those processes. Biopsies from patients with colon carcinoma show increased levels of GFAT and consequently aberrant glycans' expression suggesting an increase of HBP flow in human colon cancer. All together, our results open the possibility that HBP links hyperglycemia, aberrant glycosylation and tumor malignancy, and suggest this pathway as a potential therapeutic target for colorectal cancer.

Oncogenesis (2017) 6, e306; doi:10.1038/oncsis.2017.2; published online 20 March 2017

\section{INTRODUCTION}

Colorectal cancer (CRC) is the third most common cancer and the second leading cause of cancer death in the United States. ${ }^{1}$ Epidemiological evidences show that individuals with diabetes mellitus (DM) have significantly higher risk of developing multiple

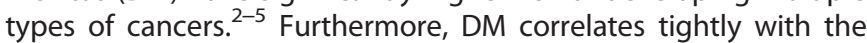
incidence and mortality of CRC. ${ }^{6-9}$

Hyperglycemia is the most important feature of DM, a hallmark for both DM1 and DM2. The excess glucose supports cancer cells' increased energetic and biosynthetic needs. ${ }^{10}$ It has been reported that high glucose $(\mathrm{HG})$ triggers several direct and indirect mechanisms that cooperate to promote cancer progression, such as induction of epithelial mesenchymal transition $(E M T){ }^{11}$ increased levels of insulin/IGF-1 and inflammatory cytokines in circulation, ${ }^{12-14}$ increased leptin and pro-survival AKT/mTOR signaling ${ }^{15}$ and enhancement of WNT/ $\beta$-catenin signaling. ${ }^{16}$ Together, these studies reveal that hyperglycemia per se has an important impact on cancer cells.

Most malignant tissues have increased fludeoxyglucose uptake associated with an increased rate of glycolysis and glucose transportation. ${ }^{17,18}$ This high glycolytic rate likely benefits proliferating cells through the production of glycolytic intermediates, which fuels metabolic pathways that generate de novo biosynthesis of nucleotides, NADPH, lipids, amino acids and glycoconjugates. Despite the fact that the majority of glucose enters glycolysis, $\sim 2-5 \%$ of a cell's glucose enters the hexosamine biosynthetic pathway (HBP), which provides UDP- $N$-acetyl-Dglucosamine (UDP-GICNAC), and its derivative UDP- $N$-acetyl-Dgalactosamine (UDP-GalNAc), and CMP-N-acetylneuraminic acid (CMP-Neu5Ac). ${ }^{19}$ These compounds are substrates for $\mathrm{N}$ - and $\mathrm{O}$-glycosylation of extracellular proteins and glycolipids, and for the post-translational modification of intracellular proteins by O-GlcNAc transferase (OGT). UDP-GIcNAc is highly responsive to variations in cell nutrients as its synthesis depends on products of the metabolism of glucose, amino acids, fatty acids and nucleotides. $^{20}$ Hence, UDP-GIcNAc can serve as a reporter for the functional status of multiple pathways, and is considered an ideal metabolic sensor. ${ }^{21}$

The rate-limiting enzyme in glucose flux through the hexosamine pathway is glutamine-fructose-6-phosphate amidotransferase (GFAT), which catalyzes the synthesis of glucosamine-6-phosphate from fructose 6-phosphate and glutamine. GFAT has two isoforms in mammals, GFAT1 and GFAT2, which are expressed in different tissues and possibly have different functions. ${ }^{22}$ Studies have shown a growing association of GFAT with metabolic diseases such as $\mathrm{DM}^{23,24}$ and cancer. ${ }^{11,20}$ In a previous study, we demonstrated that increasing the flow of metabolites through HBP, by increasing extracellular glucose concentrations or overexpressing GFAT2, provokes aberrant glycosylation of fibronectin and induces EMT in human alveolar epithelial adenocarcinoma cells (A549). ${ }^{11}$ Recently, we demonstrated that glucose is shunted to HBP during the EMT changing the glycophenotype of A549 cells. $^{20}$ Together, our results indicate that cell glycosylation senses glucose changes in the microenvironment and modulates cell plasticity.

Glycoconjugates have critical roles in different cellular processes including cellular adhesion, migration, growth, differentiation, signal transduction, receptor activation, immune response modulation, and are targets of antibodies used in cancer diagnosis and therapy. ${ }^{21,25}$ Growing evidence shows that aberrant glycosylation confers adaptive advantage to cells during oncogenic transformation in CRC. ${ }^{26,27}$ However, the direct effects of hyperglycemia in cancer cell behavior are relatively unexplored. Our hypothesis is that HG increases colon cancer malignancy by altering cell glycosylation through HBP. Here, we show that colon adenocarcinoma cells in HG presented aberrant glycosylation and increased proliferation, invasion and tumor growth. In addition,

\footnotetext{
${ }^{1}$ Instituto de Biofísica Carlos Chagas Filho, Rio de Janeiro, Brazil; ${ }^{2}$ Instituto de Bioquímica Médica Leopoldo de Meis, Universidade Federal do Rio de Janeiro, Rio de Janeiro, Brazil and ${ }^{3}$ Programa de Biologia Celular, Instituto Nacional de Câncer (INCA), Rio de Janeiro, Brazil. Correspondence: Dr AR Todeschini, Instituto de Biofísica Carlos Chagas Filho, Universidade Federal do Rio de Janeiro, Bloco D sala 03 CCS, UFRJ, Ilha do Fundao, Rio de Janeiro 21941-902, Brazil.
}

E-mail: adrianet@biof.ufrj.br

Received 11 July 2016; revised 7 November 2016; accepted 14 December 2016 
hyperglycemic mice showed an exacerbated tumor growth and metastasis. Modulation of GFAT activity leads to significant reduction of tumor growth, cell motility and metastasis. Furthermore, we showed higher levels of GFAT in human colon cancer samples compared to normal adjacent tissues. The results shown here suggest an important role of HBP for tumor progression of colon cancer, and uncover a possible new target for cancer chemotherapy.

\section{RESULTS}

High glucose concentration increases cell growth and invasion To test the effects of $\mathrm{HG}$ on cancer progression, colon adenocarcinoma MC38 cells were cultured in media containing low glucose (LG; $5 \mathrm{~mm})$ or HG $(25 \mathrm{~mm})$ concentration for over 30 days. MC38 cells cultured in HG (MC38-HG) presented increased proliferation when compared with cells cultured in LG (MC38-LG) as analyzed by population doubling time (PDT; Figure 1a). We found that HG induced the invasive potential of MC38-GFP ${ }^{+}$cells in transwell membranes coated with matrigel when compared to LG condition (Figures $1 \mathrm{~b}$ and $\mathrm{c}$ ).

Hyperglycemia governs tumor growth, homing and metastasis in vivo

We next explored the MC38-LG or MC38-HG cells' potential to induce tumor growth through ectopic injection in the flank of Euglycemic C57BL/6 mice (EuG). Results demonstrated a larger growth area and weight in the mice injected with MC38-HG cells when compared to mice injected with LG cells (Figures $2 a$ and b).

Hyperglycemia was induced in vivo by selective destruction of $\beta$-pancreatic cells with streptozotocin (STZ) treatment of C57BL/6 mice. Hyperglycemic mice displayed blood glucose levels threefold greater than those of the control animals $(P<0.0001)$ (Supplementary Figure S1A). MC38-LG cells injected in hyperglycemic mice $(\mathrm{HyG})$ do not present tumor growth potential. However, the HyG mice injected with MC38-HG cells present a tumor growth exacerbated when compared to other groups (Figures 2a and b). HyG mice tumors (Figures 2a and b) occurred earlier in $60 \%$ of the cases as shown by whole-body magnetic resonance (11 of 18; Figure $2 \mathrm{c}$ ).

Injecting MC38-GFP ${ }^{+}$cells into lateral tail vein of EuG or HyG mice, we assessed the impact of hyperglycemia in cell homing and metastasis. First, we observed an increase of MC38-HG GFP ${ }^{+}$cells' homing to lung 3 days after injection into EuG mice compared to that of MC38-LG GFP ${ }^{+}$cells (Figure 2d). The metastasis was analyzed 21 days after cell injection. Figures $2 e$ and $f$ show the images of the lung and number of metastatic nodules of the different groups. Next, the organs were homogenized and diluted for fluorescence read-out quantification (Figure 2g). Lungs of HyG mice were almost completely overtaken by metastatic nodules of MC38-HG injected cells, and correspondingly high fluorescence measurements were obtained. Besides, incubation of MC38 cells cultured in HG medium was sufficient to induce metastasis in the lungs of EuG mice. Furthermore, metastatic spread of MC38-HG cells was statistically significant as EuG mice that received MC38-LG cells presented fewer metastatic foci and lower fluorescence detection. High blood glucose contributed to increase in cell metastasis as HyG mice presented more nodules than EuG mice injected with MC38-LG cells did. These results suggest that HG induces phenotypic alterations on MC38 cells that regulate cell proliferation, homing and metastasis.

High glucose induces aberrant glycosylation

Alterations in cellular glycosylation confer advantages in terms of tumor growth, tumor dissemination and immune escape. ${ }^{28}$ Evidence demonstrated that hyperglycemia induces biosynthesis of aberrant glycoconjugates. ${ }^{11,21}$ Therefore, we investigated the glycophenotype changes of MC38 cells cultured in LG or HG by flow cytometry using an array of sugar-binding proteins (lectins, Supplementary Table SI) that identify alterations on cell surface glycosylation seen during tumorigenesis (Figure 3a). Effect of hyperglycemia on biosynthesis of glycoconjugates was time dependent (Supplementary Figure S2), and Figure 3b shows a significant increase of $\mathrm{N}$-glycans wherein the a-mannose (a-Man) of the saccharide core was branched with $\beta 1-6-G I C N A c$, generating triantennary $\mathrm{N}$-glycans (Phytohemagglutinin-L, PHA-L; $P=0.0615)$. We also observed an increase of un-substituted $a-$ GalNAc units, $O$-linked to the core protein, known as Tn antigen (Vicia villosa Lectin, VVL; $P=0.0243$ ). This observation is in agreement with the increased binding of Soybean agglutinin to a-GalNAc residues $(P=0.0018)$. Moreover, HG concentration induced cell surface hypersialylation as seen by the increase of glycoconjugates terminated with a2-6- and a2-3-linked Neu5Ac, implied by staining with Sambucus nigra agglutinin (SNA; $P=0.0170$ ), and Maackia amurensis agglutinin (MAA; $P=0.0170$ ) respectively. Increase of sialic acid expression was accompanied with reduction of terminal $\beta$-galactopyranose $(\beta-G a l p)$ unities recognized by the Peanut agglutinin (PNA; $P=0.0324$ ). In spite of increase of saccharide unities derivate from hexosamine pathway, augmented expression of glycoconjugates containing a-fucose (a-Fuc) observed by the increase of Aleuria aurantia agglutinin (AAL; $P=0.0329$ ) binding was also detected (Figure $3 b$ ). Hyperglycemia induces the same glycophenotypic changes in the 4T1 murine mammary carcinoma cell line from a BALB/cfC3H (Supplementary Figure S3) revealing that HG effect on glycosylation is not cell specific.
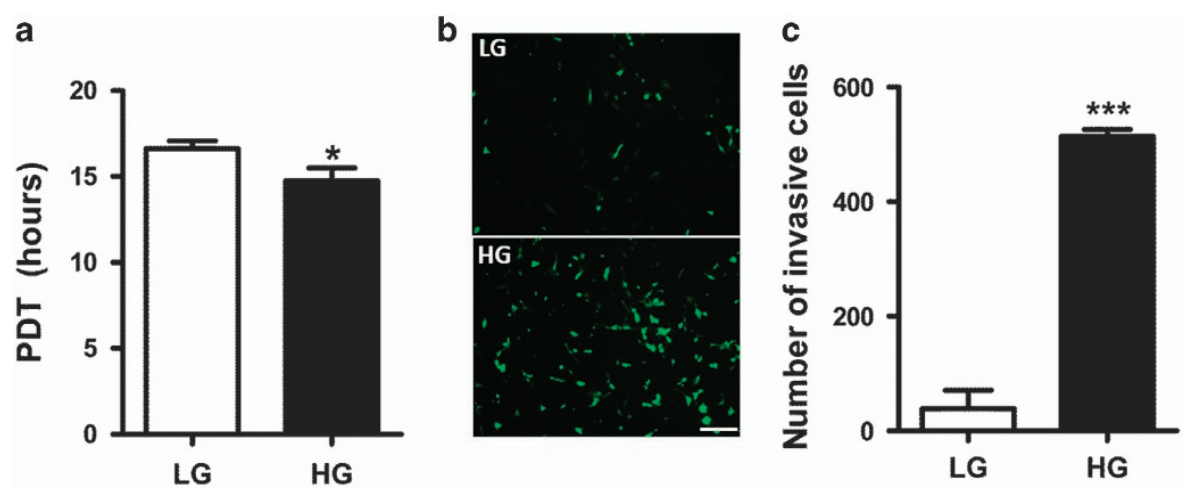

Figure 1. Hyperglycemia increases proliferation and invasion in MC38 cells. (a) Population doubling time (PDT) of MC38 cells cultured in high (HG) or low glucose (LG) concentration. $n=(3)$; error bars indicate mean \pm se.m. (b) Photomicrography of lower chamber of transwell Matrigel-coated membrane of (LG and HG) MC38-GFP cells. (c) All cells that invaded to the lower chamber were counted after $24 \mathrm{~h}$ of incubation. $n=3 ;{ }^{* * *} P<0.0001 t$ test; scale bar, $100 \mu \mathrm{m}$. 


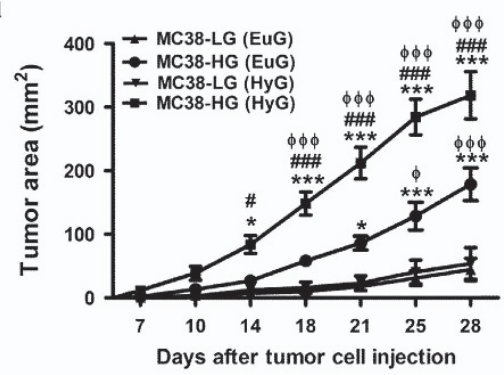

b

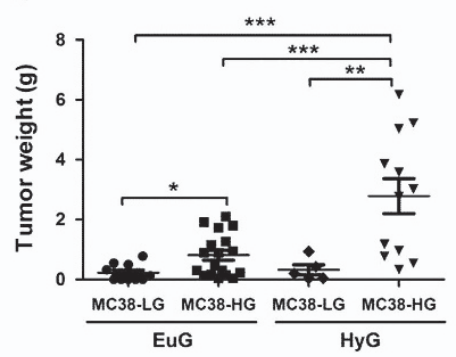

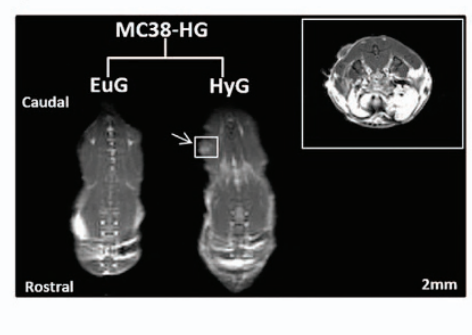

d

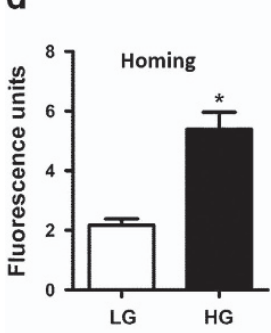

e

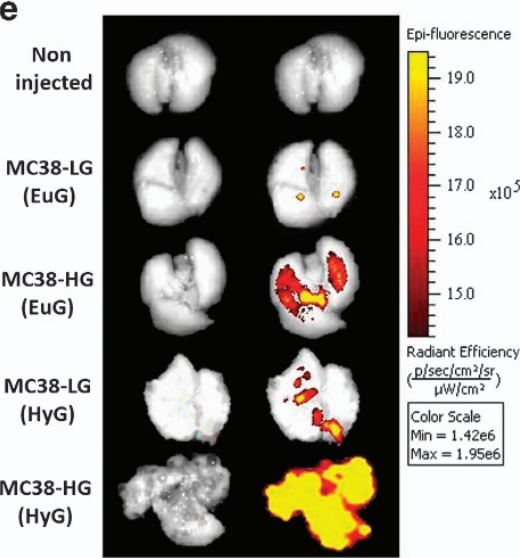

f

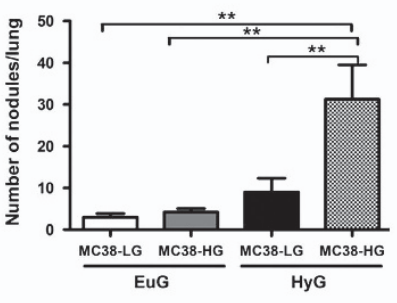

g

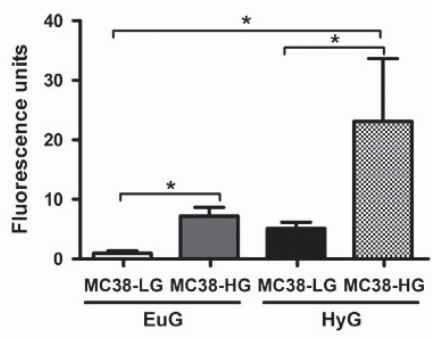

Figure 2. Hyperglycemia exacerbates tumor progression in vivo. (a) Tumor area and (b) weight of MC38-LG or MC38-HG injected in the flank of euglycemic (EuG) and hyperglycemic (HyG) mice. $n=9-18$ per group; error bars indicate mean \pm s.e.m.; ${ }^{*} P<0.05,{ }^{* *} P<0.001,{ }^{* * *} P<0.0001$, $\left.{ }^{\#} P<0.05, \# \# P<0.0001 ;{ }^{*}\right)$ represents comparison between MC38-HG and MC38-HG (HyG) with MC38-LG; (\#) is relative to comparison between MC38-HG and MC38-HG (HyG). Anova two way, Bonferonni post test. (c) Magnetic resonance whole body of euglycemic (EuG) and hyperglycemic (HyG) mice, 5 days after subcutaneous MC38-HG cells injection. (d) Fluorescence levels of lung of euglycemic mice, 3 days after injection of MC38-GFP-LG or MC38-GFP-HG cells into lateral tail vein. $n=3$ per group. (e) Representative fluorescent images of lung 21 days after MC38-GFP cell infusion. The picture shows five distinct groups: Non-injected mice; euglycemic mice (EuG) injected with MC38-LG or MC38-HG cells; hyperglycemic mice (HyG) injected with MC38-HG or MC38-LG. After the acquisition of images, the nodules were counted (f) and lung was homogenized and diluted for a fluorescence read-out (g); $n=5$ per group, ${ }^{*} P<0.05$; ${ }^{* *} P<0.001 ; \pm$ s.e.m.; one-way ANOVA; Tukey's multiple comparison test.

Results showing that $\mathrm{HG}$ increases the biosynthesis of oligosaccharides carrying hexosamines suggest an increase in HBP flux. As the levels of GFAT1 or 2 do not increase under HG concentrations (Supplementary Figure S4), we analyzed the impact of hyperglycemia in the biosynthesis of the final product of HBP, UDP-GICNAC. Using liquid chromatography with porous graphitic column, we were able to demonstrate that cells cultured in HG in vitro synthesize more UDP-hexosamines (UDP-GlcNAc and UDP-GalNAc) than MC38 cells cultured in LG (Figure 3c). By using high-resolution matrix-assisted laser desorption/ionization Fouriertransform ion cyclotron resonance mass spectrometry imaging (MALDI-FT-ICR MSI) on tissue samples, we accessed the impact of hyperglycemia in production of UDP-GICNAc in subcutaneous tumors from EuG and HyG mice. Matrix-assisted laser desorption/ ionization mass spectrometry imaging (MALDI-MSI) is a powerful technique combining mass spectrometry with histology, allowing for the spatially resolved and label-free detection of hundreds to thousands of compounds within a single tissue section. ${ }^{29}$ Figure $3 d$ shows localizations for different $\mathrm{m} / \mathrm{z}$ values in subcutaneous tumors from EuG and HyG mice. From Figure $2 \mathrm{c}$ it is clear that the $[\mathrm{M}-\mathrm{H}]^{-} \mathrm{m} / \mathrm{z} 606.073$ relative to UDP-hexosamines is mostly present on tissue from HyG mice. In contrast, NADPH $(\mathrm{m} / \mathrm{z}$ 743.074), a product of pentose phosphate pathway, is present across both samples, but most intensely in tumor from EuG mice. It is noteworthy that the $\mathrm{m} / \mathrm{z} 606.073$ presents a distribution similar to that of the ion $\mathrm{m} / \mathrm{z} 202.107$ related to acetylcarnitine, a marker for hypoxic tumor regions. ${ }^{30}$ Therefore, sustained hyperglycemia increases UDP-GICNAc biosynthesis.
In agreement with alterations in the pool of activated hexosamines, histochemistry of subcutaneous tumors showed an increase of glycoconjugates containing a2-6-linked Neu5Ac residues (SNA), with simultaneous reduction of PNA binding to terminal $\beta$-Galp unities (Figure $3 \mathrm{~d}$ ). Besides, increase of a-Fuc residues $(A A L)$ corroborates with in vitro results.

GFAT determines tumor growth, invasion and aberrant glycosylation

To gain insight into whether effect of HG on tumor progression is associated to glucose assimilation into HBP, we pre-treated the GFP-MC38-HG cells with the pharmacologic inhibitor of GFAT, 6-Diazo-5-oxo-L-norleucine (DON). DON treatment decreased MC38-HG proliferation, as measured by PDT assay (Figure 4a). DON significantly impaired tumor growth of MC38-HG treated cells injected in the mice flank of EuG mice (Figures $4 b$ and $c$ ). Moreover, DON presented a tendency to decrease the homing to lung 3 days after cell injection (Supplementary Figure S5). Besides, DON treatment reduced the invasiveness of MC38 cells in transwell membranes coated with matrigel (Figure 4d, upper panel). As DON is not a specific inhibitor of GFAT, as it inhibits other amidotransferases, we tested whether the addition of GlcNAc can restore cell invasion by bypassing GFAT inhibition by DON. It is well established that O-GIcNAc is highly responsive to the HBP. ${ }^{31}$ Our results clearly showed that DON decreased $O$-GlcNAc levels, whereas the addition of GlcNAc can increase the O-GlcNAc levels, even in the presence of DON (Figure $4 d$, lower panel), indicating that the DON effect observed in our 
model is due to HBP inhibition. As illustrated in Figure 4d (upper panel), GlcNAc increases cell invasion; besides, addition of GlcNAc to DON-treated MC38-HG cells partially restores the ability of cells to invade, thus, decreasing DON inhibition. These results reinforce the role of GFAT in tumor progression.
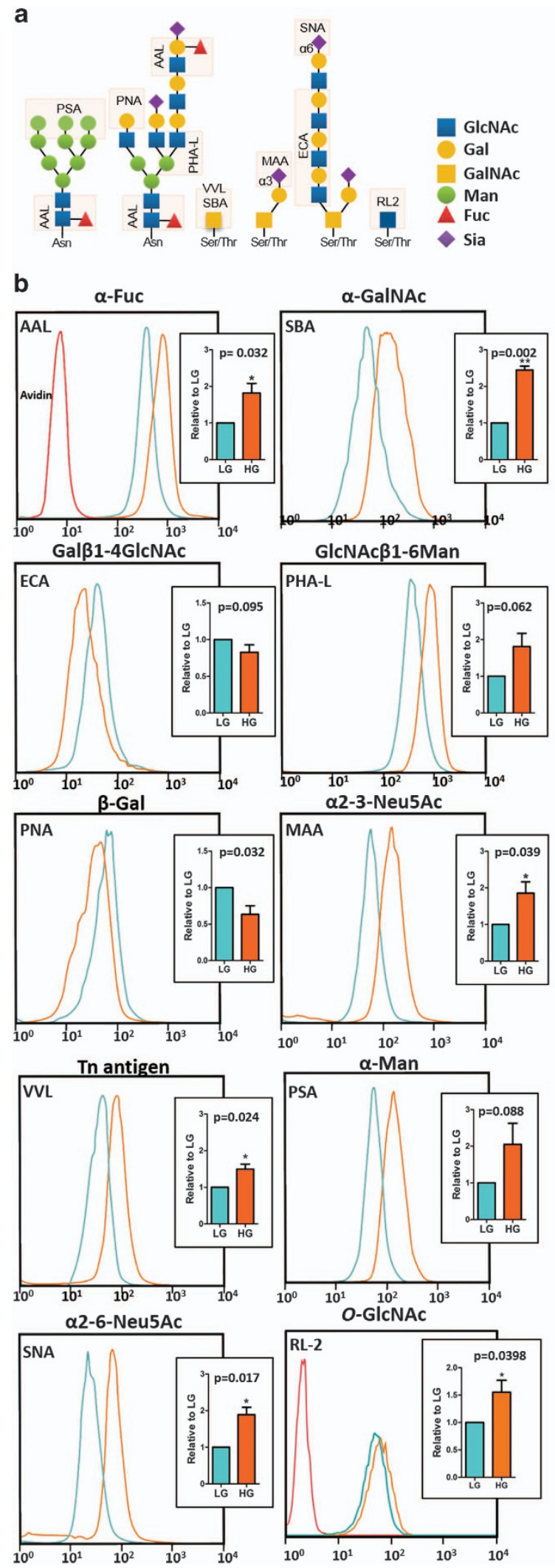

To further substantiate the role of GFAT in tumor progression induced by hyperglycemia, we assessed the impact of its gene knockdown in the MC38-HG cells (Figures $5 \mathrm{a}$ and b). In agreement with above results using DON, downregulation of GFAT protein levels reduced tumor growth in vivo (Figures $5 \mathrm{e}-\mathrm{g}$ ), although it
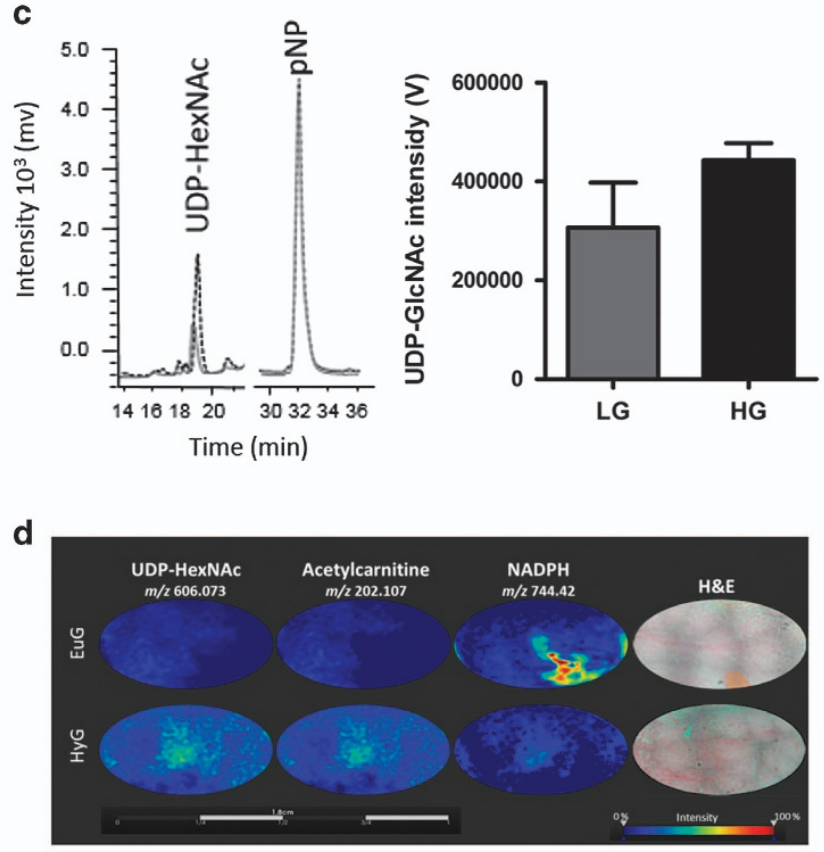

e

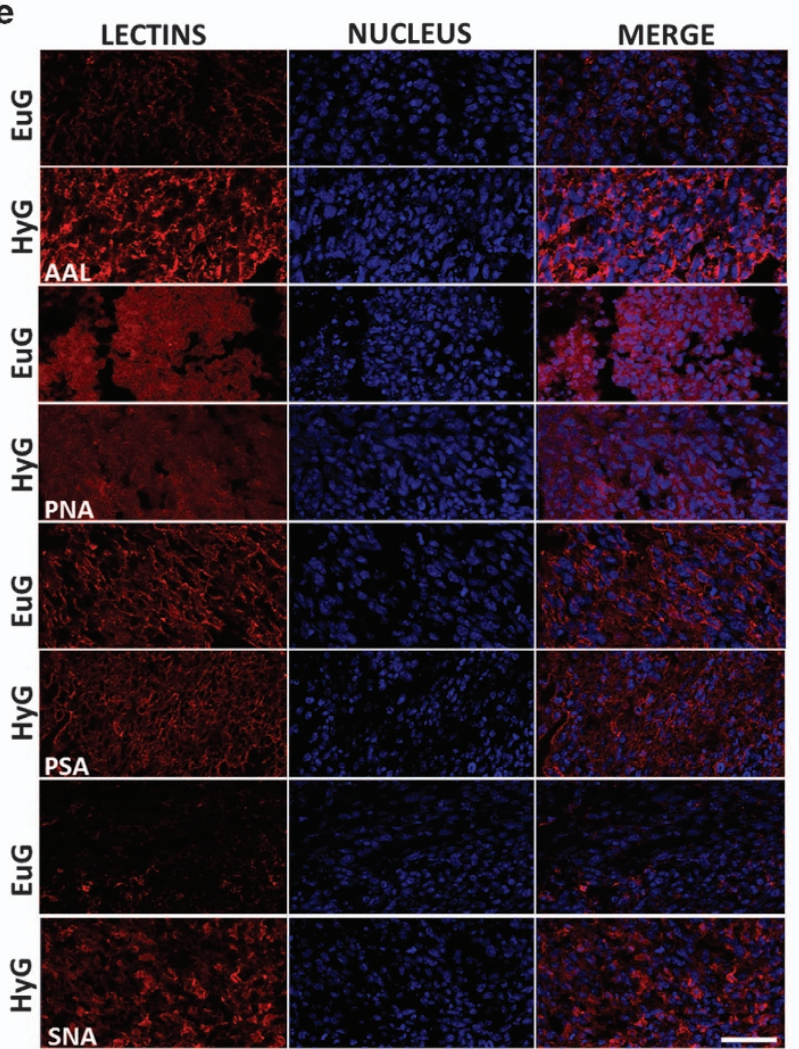


appears to have no effect in the proliferation assay (Figure $5 c$ ). The high invasion capacity observed in the HG cells (Figures $1 \mathrm{~b}$ and $\mathrm{c}$ ) was strongly decreased in the shGFAT group (Figure 5d). Moreover, the experimental metastasis analysis shows that GFAT deficiency significantly attenuates metastatic spread of
shGFAT-MC38 cells to the lungs of HyG animals compared to shScramble-MC38 cells (Figure 5 h). Quantitation of nodules shows that shGFAT-MC38 cells yielded one or two measurements, just at the level of detection (Figure 5i). Thus, GFAT silencing dramatically inhibits metastasis of this aggressive tumor. a

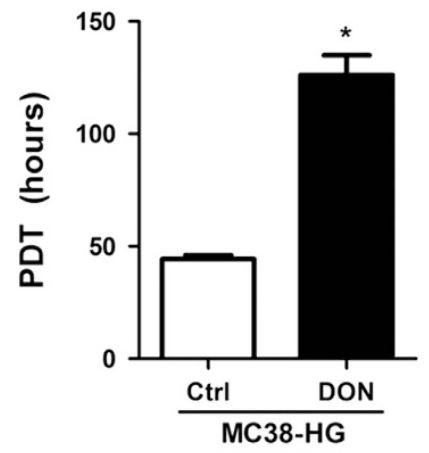

b

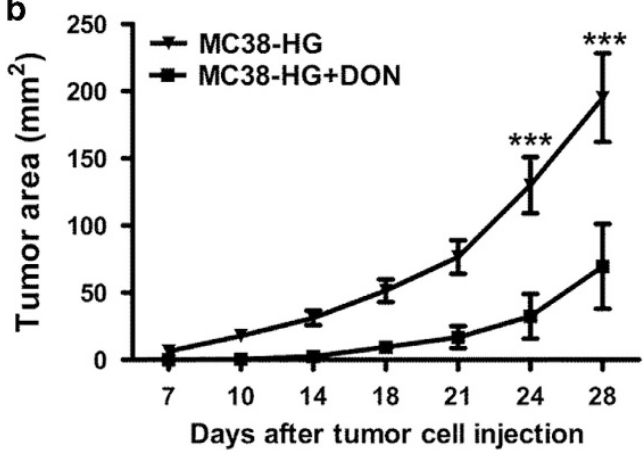

C

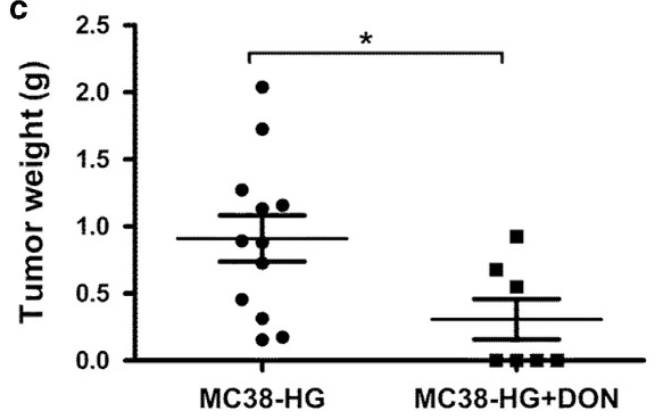

d
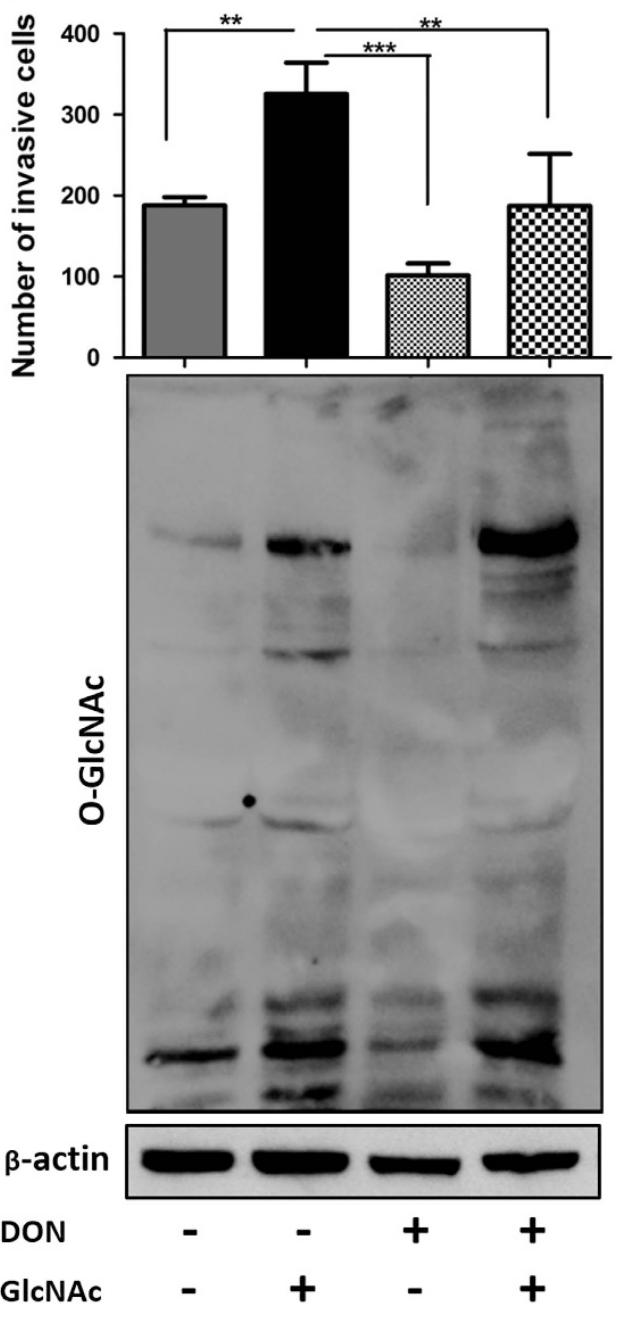

GIcNAc

Figure 4. Pharmacological inhibition of GFAT decreases tumor growth and invasion. (a) Proliferation analysis of MC38-HG cells cultured in the absence (Ctrl) or presence of $1 \mu \mathrm{M}$ DON (DON). $(n=3)$; error bars indicate mean \pm s.e.m.; $t$-test. (b) Tumor area and (c) weight of MC38-HG cells untreated, or treated, with $1 \mu \mathrm{M} \mathrm{DON} \mathrm{(MC38-HG+DON)} \mathrm{and} \mathrm{injected} \mathrm{in} \mathrm{the} \mathrm{flank} \mathrm{of} \mathrm{euglycemic} \mathrm{mice.} \mathrm{MC38-HG}(n=12)$; MC38-HG+DON $(n=7)$. (d) Lower panel. Western blot analysis of lysate from MC38-LG cells treated with Mannitol (osmotic control), GlcNAc, DON and DON+GlcNAC analyzing O-GlcNAc levels and $\beta$-actin expression. Upper panel. Invasion of MC38-LG cells treated with Mannitol (osmotic control, 40 mM), GICNAC $(40 \mathrm{~mm})$, DON $(1 \mu \mathrm{M})$ and DON+GlcNAc by transwell analysis of $24 \mathrm{~h}$ of incubation; $n=3, \pm$ s.e.m.; one-way ANOVA, Bonferroni's multiple comparison test ${ }^{*} P<0.05 ;{ }^{*} P<0.001 ;{ }^{* *} P<0.001$

Figure 3. Hyperglycemia induces aberrant glycosylation. (a) Scheme representing binding specificities of the lectins and RL2 antibody used in this study. (b) Flow cytometry histograms show representative binding profile of different lectins in MC38 cells cultured in high (HG, orange) or low glucose (LG, blue) concentration. Red empty histogram refers to cells stained with the FITC-conjugated streptavidin, and bar graph shows the differences between the fluorescence intensity for each lectin. O-GlcNAc labeling was accessed by immunolabeling with RL2 antibody, and its red histogram represents cells stained with Alexa Fluor 488-conjugated antibody. The results represent four experimental replicates. $(n=4)$; unpaired $t$-test. (c) Left, chromatograms of polar metabolites of cell extracts from MC38-LG (gray line) and MC38-HG cells (black dashed line), showing regions corresponding to UDP-HexNAc and pNP retention times. Right, UDP-HexNAc quantification of MC38-LG (gray) and MC38-HG cells (black). Quantitative analyses are shown as mean \pm s.d. of two independent experiments. (d) Comparison of $m / z$ localization in subcutaneous tumor from euglycemic and hyperglycemic mice. MALDI-MSI analysis showing the distribution of $m / z 606.073$ (UDP-hexosamine), $m / z 202.10$ (acetylcarnitine) and $m / z 743.074$ (NADPH) and right panels are H\&E-stained. (e) Lectin binding to tumor tissue of hyperglycemic versus euglycemic mice. Photomicrografies are representative of subcutaneous tumor tissue from hyperglycemic (HyG) versus euglycemic (EuG) mice analyzed 28 days after MC38 implantation. Scale bar, $100 \mu \mathrm{m} .(n=3)$. 
a

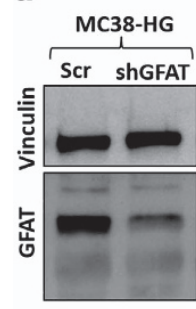

b

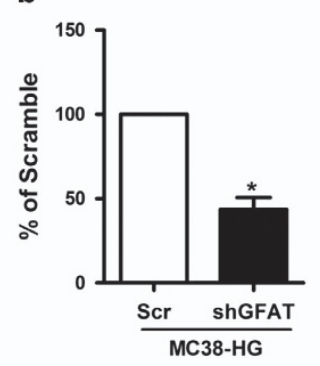

C

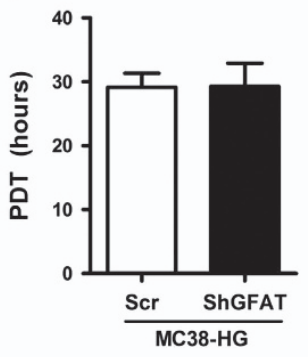

f

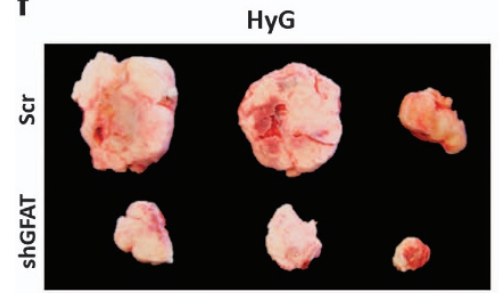

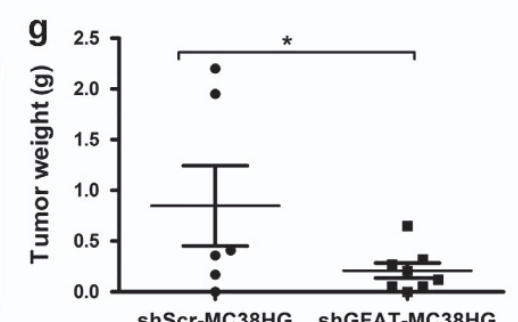

d

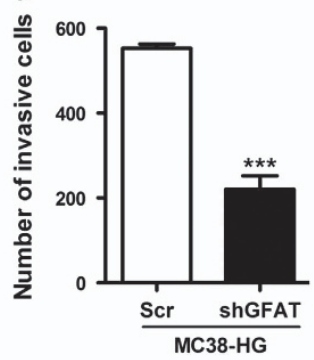

h

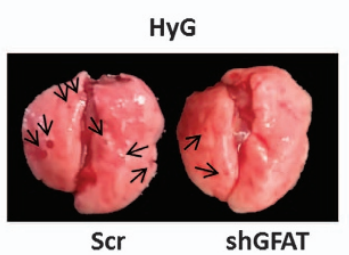

e
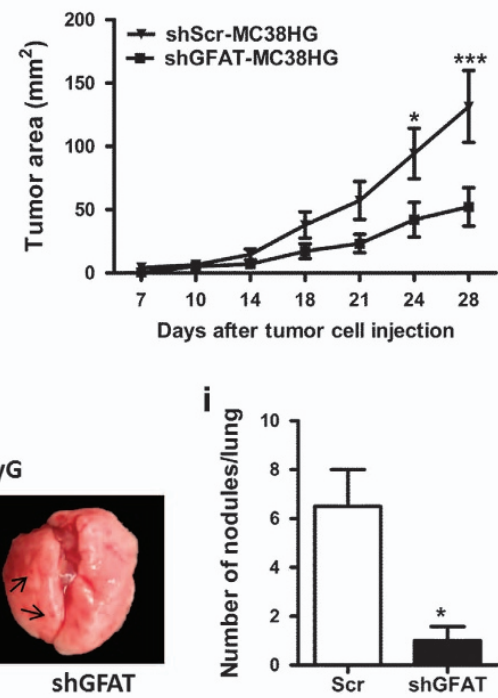

Figure 5. Effect of GFAT deletion on tumor progression. (a, b) Protein expression of GFAT in shGFAT-MC38 cells. ( $n=4)$. (c) The population doubling time (PDT) analysis of Scrambled MC38-HG cells related to shGFAT MC38-HG cells. (d) The Matrigel-coated chamber transwell invasion assay of shGFAT MC38-HG cells compared to that of Scrambled MC38-HG cells. (e) Tumor area, (f) representative images and (g) weight of euglycemic (EuG) mice injected subcutaneously with shGFAT MC38-HG cells or Scrambled MC38-HG cells ( $n=6-8$ ). (h) Representative images and (i) quantification of lung metastatic nodules in hyperglycemic (HyG) mice injected with shGFAT MC38-HG cells or scrambled MC38-HG cells $(n=5)$. Results are expressed as mean \pm s.e.m.; two-tailed, unpaired $t$-test and Anova two way; Bonferonni post test. ${ }^{*} P<0.05,{ }^{* * *} P<0.001$.

Figure 6 shows that GFAT downregulation significantly decreased expression of triantennary $N$-glycans branched with $\beta 1-6$ GlcNAc as seen by decrease of L-PHA binding $(P=0.0218)$. Likewise, decrease of GFAT expression caused a drop in the biosynthesis of Tn antigens (VVL binding). The decrease in SNA binding $(P=0.0252)$ with an associated increase of terminal $\beta$-Galp unities recognized by PNA $(P=0.0397)$ and ECA $(P=0.0065)$ upon GFAT downregulation is consistent with the participation of HBP in glycan decoration by a2-6-linked Neu5Ac. It is well established that $O$-GlcNAcylation is highly responsive to HBP. ${ }^{20}$ Here, we analyzed the O-GIcNAcylation by flow cytometry using the RL2 antibody after cell membrane permeabilization. As expected, the O-GlcNAc levels were significantly decreased in the shGFAT1 cells.

GFAT is overexpressed in human colon cancers.

Our data suggested an important role for HBP in murine colon cancer and motivated us to investigate whether this pathway is altered in human colon cancer. In this direction, we analyzed GFAT mRNA and protein levels from adenocarcinoma (T) and adjacent normal tissues $(\mathrm{N})$ of colon cancer patients. Our data demonstrated a significant increase of GFAT2 mRNA (Figures 7e and f). Western blot analysis revealed that the protein expression for the GFAT1 (Figures 7a and b), GFAT2 (Figures 7a and c) and O-GlcNAcylation (Figures $7 a$ and d) also was remarkably increased in tumor tissue when compared with the adjacent normal tissues. In addition, dot blot analyses revealed a cancer-related increase of sialylation (Figures $7 \mathrm{~g}$ and $\mathrm{h}$ ). These data suggest an increase of HBP products in tumor tissues.

\section{DISCUSSION}

It is widely known that aberrant glycosylation is implicated in many cancer types including $\mathrm{CRC}{ }^{26}$ Alterations in cell surface glycosylation directly impact cell growth, survival and promote invasive behavior of tumor cells that, ultimately, lead to metastasis and progression of cancer. ${ }^{28}$ Here we show that increasing extracellular glucose concentration provokes aberrant glycosylation, increased cell proliferation and invasion, presenting an important role in tumor progression. By downregulating GFAT, we demonstrate that HBP is involved in those processes. Hyperglycemic mice show an accelerated development of subcutaneous tumors displaying aberrant glycoconjugates. Furthermore, the experimental metastasis model also presented a more aggressive profile in hyperglycemic mice. Taken together, our results allow us to infer that an increase of glucose levels induces the biosynthesis of aberrant glycoconjugates, and increases tumor progression of murine colon carcinoma cell MC38 through HPB since GFAT downregulation decreases aberrant glycosylation and cell malignancy. In agreement with the experimental data, biopsies from patients with colon carcinoma express more GFAT and aberrant glycans, when compared with adjacent normal tissue. These data suggest an increase of HBP flow in human colon cancer.

Recently, hyperglycemia has been considered a risk factor that links DM to cancer progression. ${ }^{16,32,33}$ Hyperglycemia effect has been extensively demonstrated on cell proliferation ${ }^{15,34-38}$ and metastasis. ${ }^{39-42}$ Among those reports an epidemiology study demonstrated that, in cancer patients with DM2 or hyperglycemia, the proportion of tumor recurrence, metastasis, or fatal outcome is higher than that in patients without metabolic disease. ${ }^{42}$ Epidemiological studies also support an antineoplastic role for metformin, an anti-hyperglycemic drug, on cancer risk. ${ }^{43}$ Metformin inhibits cancer cell proliferation in vitro ${ }^{44}$ and suppresses colon carcinoma growth in vivo. ${ }^{45,46}$ Furthermore, Metformin treatment can significantly lower the risk of CRC in DM2 patients. ${ }^{47}$ These reports are in agreement with our findings showing that hyperglycemia induces tumor growth, cell invasion homing and metastasis.

Although the underlying mechanisms behind hyperglycemia and cancer association have not been elucidated, inflammation, oxidative stress and immunosuppression are potentially involved in tumor progression in various ways. ${ }^{48}$ Our data showing that incubation of MC38 cells cultured in HG medium was sufficient to induce growing of subcutaneous tumors, homing and metastasis into the lungs of EuG mice rule out the effect of hyperglycemia on host inflammation and immune system. Besides, these results 

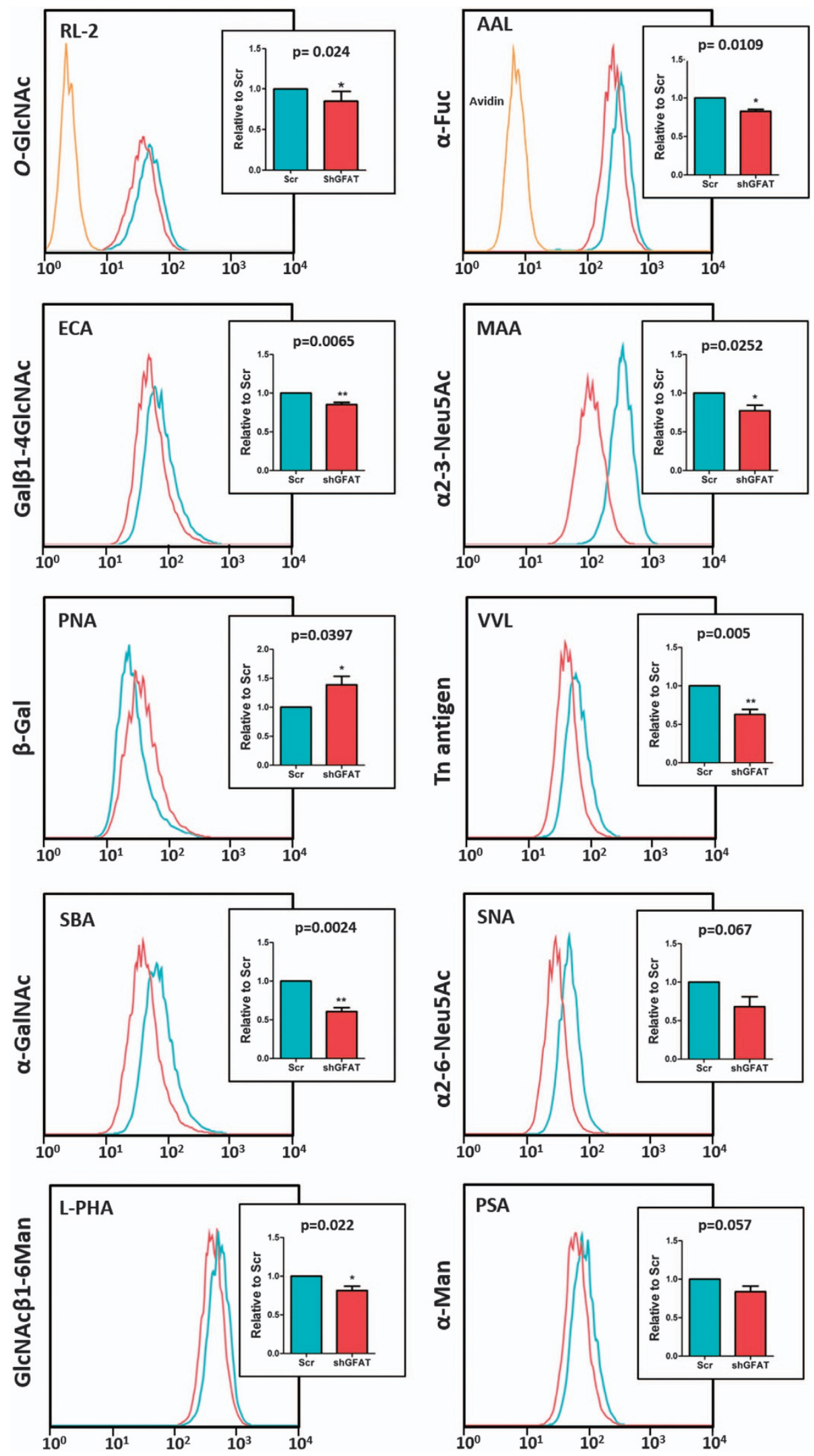

Figure 6. Reduction of aberrant glycosylation in GFAT silenced MC38 cells. Flow cytometry histograms of lectin binding and O-GlcNAC immunolabeling. The histograms show representative binding profile of different lectins and O-GlcNAc immunolabeling in Scrambled MC38-HG cells (Scr, green) or shGFAT MC38-HG cells (red). Yellow empty histogram refers to cells stained with the FITC-conjugated streptavidin and Alexa Fluor 488-conjgated antibody. Bar graph shows the differences between the fluorescence intensity for each marker. $n=4$ per group; error bars indicate mean \pm s.e.m. Unpaired $t$-test. 
a
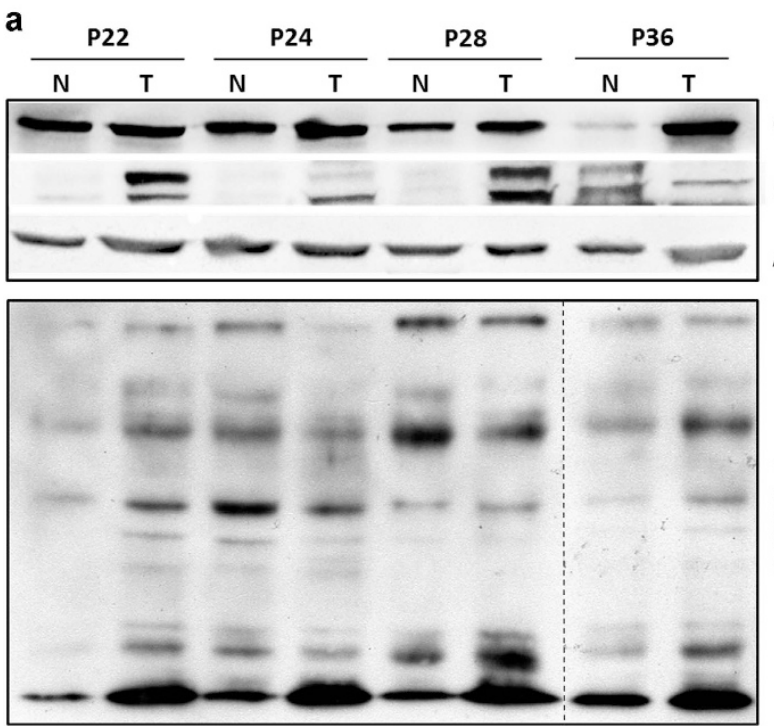

GFAT1

GFAT2 Actin

\section{Actin}
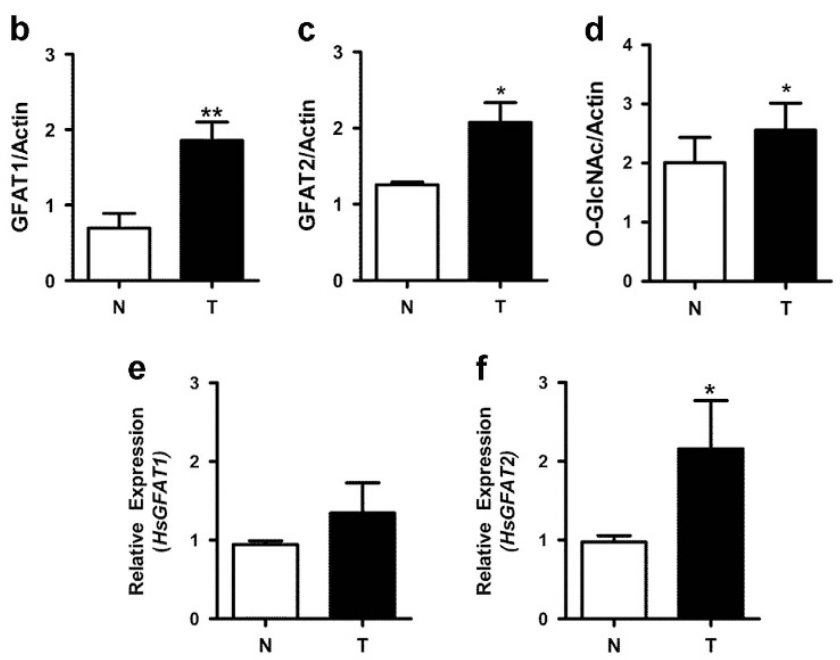

g

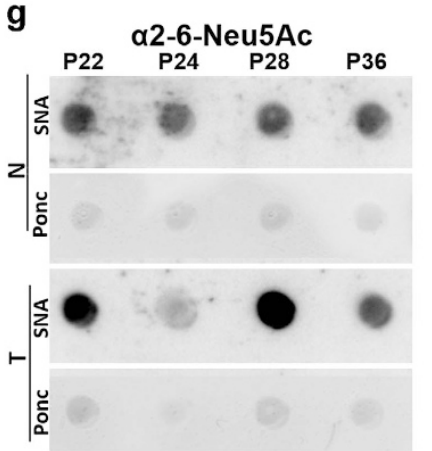

h

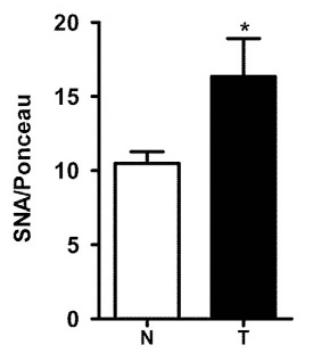

Figure 7. Aberrant levels of GFAT, SNA and O-GICNAc in human colon tissue. (a-d) Western blot analysis of human colon adenocarcinoma (T) and adjacent normal tissue (N) to GFAT1, GFAT2, O-GIcNAc and actin. (e, f) GFAT1 and GFAT2 mRNA levels in tumor (T) versus adjacent normal tissue $(\mathrm{N})$. (g, h) Dot blot analysis in tumor $(\mathrm{T})$ and adjacent normal tissues $(\mathrm{N})$, measuring the SNA levels. The images are representative from four patients (P22, P24, P28 and P36). All graphs represent means \pm s.e.m.; one-tailed unpaired $t$-test; total number of seven patients $n=7$; ${ }^{*} P<0.05$.

raise the hypothesis that hyperglycemia imprints a memory in MC38 cells (see Discussion below).

Effect of high levels of glucose might be due to an increase of glucose transporters (GLUT), ${ }^{34,35,49}$ increasing glucose uptake. ${ }^{49}$ Indeed, tumor cells have a HG uptake through increased expression of GLUT transporters. ${ }^{50}$ Thus, cancer cells might benefit from HG concentration. Once inside the cell, glucose is phosphorylated by hexokinases forming glucose-6-phosphate that can be shunted into the pentose phosphate pathway by glucose- 6 phosphate dehydrogenase or undergo enzymatic isomerization, forming fructose-6-phosphate. Even though the majority of glucose enters glycolysis, $2-5 \%$ of total glucose within cells enters $\mathrm{HBP}$, generating UDP-GIcNAc, and its derivatives, UDP-GalNAc and CMP-Neu5Ac-donor substrates used in the production of glycoproteins and glycolipids. ${ }^{19}$ Thus, HBP links the altered metabolism with aberrant glycosylation, providing a mechanism of how cancer cells can sense and respond to microenvironment changes. Our group has shown that A549 cells increase glucose uptake during EMT; however, instead of increasing the glycolysis and pentose phosphate pathway, glucose is shunted through the $\mathrm{HBP}$, resulting in a significant increase of UDP-GICNAC and aberrant glycosylation. ${ }^{20}$ Here we show that MC38-HG cells and tumors from hyperglycemic mice present more UDP-GlcNAc than MC38-LG cell and tumors do from euglycemic mice. Therefore, sustained hyperglycemia would lead to excess UDP-GIcNAc, and its derivatives. Growing evidence demonstrates that alterations in the pool of activated substrates might lead to differential glycosylation. ${ }^{51}$ Also, glycosylation changes are associated with multiple steps of CRC progression. ${ }^{26}$ Our results show that hyperglycemia induces surface glycophenotype alterations both in vitro and in vivo, favoring malignant cell phenotypes. HG increased the levels of $\mathrm{Tn}$ antigen, a2,6-sialylation, a2,3-sialylation, fucosylation, complex $\beta 1,6$-branched N-linked glycans and intracellular O-GlcNAcylation. These results are in accordance with the aberrant glycosylation observed in human colon tumor. ${ }^{52-54}$ Indeed, a-fucosylation is seen in numerous types of tumors, including colorectal ${ }^{55-59}$ and it is correlated with tumor metastasis, disease recurrence and poor survival of patients. ${ }^{60}$ However, mutations in GDP mannose-4,6-dehydratase (GMDS) impairing GDP-fucose biosynthesis contribute to the escape of CRC from immune surveillance, indicating that loss of function of fucosylation facilitates cancer progression.61,62 Therefore, enhanced fucosylation has been proposed to be an early event in cancer, whereas glycans are again defucosylated with cancer progression and metastasis. ${ }^{26,61-64}$

The expression of Tn antigen (GalNAc-O-Ser/Thr), is associated with earlier stages of CRC, whereas their sialylated counterparts are overexpressed in later stages, also known as metastatic stage. ${ }^{65,66}$ These results are in agreement with our previous work showing that hyperglycemia provokes aberrant $O$-glycosylation and upregulation of mRNA levels for UDP-GalNAc: polypeptide Nacetylgalactosaminyltransferases (ppGalNAc-T6), ${ }^{11}$ the enzyme that catalyzes the biosynthesis of Tn antigen. Besides, here we observed that hyperglycemia induces an increase of glycoconjugates decorated with a2-6Neu5Ac (SNA labeling). Increased sialic acid on the surface of tumor cells is well described in the literature 
of several tumor types. Increased expression of a2-6-linked sialic acids on $\mathrm{N}$-glycans was associated with cancer progression, occurrence of metastasis, poor prognosis and therapeutic failure in CRC due to decreased cell-cell interactions and increased invasiveness. ${ }^{67}$ There is evidence that all this pro-tumor role of a2-6-linked sialic acids on $\mathrm{N}$-glycans is related to maintenance of stemness in CRC cells. ${ }^{68}$ Furthermore, upregulation of ST6Gal1 on colorectal adenocarcinoma cells was shown to increase the a2-6-sialylation of $N$-glycans on $\beta 1$-integrin adhesion receptors. ${ }^{69}$ Sialylation of these receptors increases their interaction with the cytoskeletal-associated protein talin as well as their binding and haptotactic migration on collagen, thereby leading to enhanced tumor progression. Expression of glycans decorated by a2-3-linked sialic acid (MAA labeling) found here is in accordance with studies showing a2-3-sialylation to be elevated in metastatic colon cancer cell lines. ${ }^{70}$ a2-3-sialylated glycans are major components of cancer-associated sialyl Lewis antigens which play an important role in E-selectin-mediated cancer cell adhesion to vascular endothelial cells during the course of hematogenous metastasis. $^{71}$ Thus, influence of hyperglycemia on expression of sialyl Lewis oligosaccharide by MC38 cells must be verified. Sialylation is often associated with the decrease of outer $\beta-G a l$ units, thus, reducing labeling by PNA. Given that terminal $\beta-G a l$ residues are implicated in apoptosis of tumor cells mediated by galectins (a family of carbohydrate-binding proteins with an affinity for $\beta$-galactosides, secreted by a variety of cells including the immune system), sialylation on the surface of tumor cells might protect tumor cells from infiltrating immune cells. ${ }^{72}$ Therefore, hypersialylation seen here might favor the evasion of the immune system. It is noteworthy that hyperglycemia increases the expression of complex $\beta 1-6$-branched N-linked glycan, as seen by increase in L-PHA binding. The $\beta 1-6$ GlcNAc-branched oligosaccharide is a product of Mgat5 activity. Mgat5 activity is limited by UDP-GIcNAc concentration, thus, increased availability of this activated substrate highly increases the $\beta 1-6 \mathrm{GlcNAc}$ branched product. ${ }^{73}$ Metabolite availability to the HBP and Golgi increases the number of $\mathrm{N}$-glycans and $\mathrm{N}$-glycan branching per protein molecule. $\mathrm{N}$-glycans are ligands for galectin 1 and 3 at the cell surface, forming lattices that enhance the residence time of receptors as glucose transporters (GLUT4, GLUT2). ${ }^{74,75}$ $\mathrm{N}$-glycosylation indirectly affects metabolism by regulating the surface expression of growth factors receptors, which activate signal transduction pathways that regulate cell growth and metabolism. ${ }^{73,75}$ Together with previous data, ${ }^{2,11,73,76}$ we might suggest that hyperglycemia influences localization and organization of surface glycoproteins.

UDP-GICNAC is the donor substrate for OGT, the enzyme responsible for addition of GlcNAc in $\beta$-glycosidic linkage to serine or threonine hydroxyls of cytoplasmic and nuclear proteins. Thus, $O$-GlcNAcylation is extremely responsive to increases in glucose uptake. $^{31,77}$ Onodera et al. ${ }^{38}$ showed that O-GlcNAcylation of some proteins was observed only in malignant cells, and glucose deprivation or inhibition of HBP or OGT significantly reduced tumor-specific O-GlcNAcylation in 3D cultures. Many authors have reported that several cancer types, including breast, bladder, prostate and colon display higher levels of OGT or O-GIcNAcylation in grade II or III tumors in comparison to grade I cancers indicating an association with malignancy. ${ }^{78}$ These reports are in agreement with our observation that expression of O-GlcNAcylated proteins in patient tumor tissues is higher when compared with the adjacent normal tissues. Although further studies are required, we can suggest that intracellular $\mathrm{O}$-GlcNAcylation might control cell surface sialylation, given that it was demonstrated very recently that the activity of UDP-N-acetylglucosamine 2-epimerase/ $\mathrm{N}$-acetylmannosamine kinase (GNE), the key enzyme for the biosynthesis of sialic acids, is modulated by aberrant O-GlcNAcylation. ${ }^{79}$
Recently, O-GIcNAc has emerged as an epigenetic regulator of gene expression through its influence on higher-order chromatin structure, transcription and modulation of RNA polymerase II. ${ }^{80,81}$ Thus, it is suggested that O-GlcNAcylation might link hyperglycemia to epigenetic. ${ }^{81,82}$ Indeed, growing evidences have demonstrated that prolonged exposure to HG epigenetically affects gene expression to the level that alterations remain stable in the absence of hyperglycemia, an effect known as Hyperglycemic memory. ${ }^{83}$ Numerous cancerous changes in gene transcription and genome organization have been shown to be highly dependent on epigenetic mechanisms ${ }^{84}$, and epigenetic modulations of oncogenic pathways induced by HG results in prolonged activation of cancer cell proliferation. ${ }^{85}$ Our data suggest that HG prints glycophenotype memories in MC38 cells that remain stable out of the hyperglycemic environment, which are recovered under high blood glucose. Epigenetic regulation of glycosylation is a relatively new emerging concept but with enough studies completed to highlight its importance. ${ }^{86-88}$ MGAT5B, the coding gene for $\mathrm{N}$-glycan branching enzyme GnT-IX, is regulated by epigenetic mechanism involving chromatin activation by the OGT-TET3 complex. ${ }^{89,90}$ In future studies, it would be interesting to investigate the influence of hyperglycemia in histone modifications for the other glycan genes.

To evaluate the importance of GFAT in tumorigenesis of colon cancer, we modulated the flux of substrates through HBP. Apart from using $\mathrm{HG}$, another method for driving increase in HBP influx is to treat cells with GlcNAc, which enters the HBP, bypassing GFAT. Alike observed for HG, GlcNAc increased cell invasiveness. Oppositely, GFAT pharmacological inhibition by DON decreased cell invasion. Data showing that GlcNAc reverts DON inhibition proves that its effect on cell invasion is due to GFAT inhibition. Next, we silenced the rate-limiting enzyme GFAT1. This strategy allowed us to show that GFAT1 controls tumor growth and invasion, and aberrant glycosylation. Corroborating these data, we observed an increase in the levels of GFAT1 and GFAT2, as well as $O-G l c N A c y l a t i o n$ and sialylation, in human colon adenocarcinomas, suggesting an important role of HBP in cancer progression. GFAT overexpression has been observed in prostate cancer biopsies before ${ }^{91}$, and its activity appears to be associated with postprandial hyperglycemia in DM2 patients. $^{23}$ In summary, our data suggest that HBP may be altering the tumor cell biology and accelerating the malignancy process through aberrant glycosylation. Our results suggest the HBP as one mechanism by which hyperglycemia is involved in cancer progression and may point toward a potential pathway amenable for therapeutic intervention.

\section{MATERIALS AND METHODS}

Cell culture

Mouse colon adenocarcinoma cell line MC38 and the engineered MC38 cells expressing Green fluorescent protein ${ }^{92}$ were kindly donated by Ajit Varki (University of California, San Diego, CA, USA). The human alveolar basal epithelial A549 cells were purchased from American Type Culture Collection (ATCC, USA). All cell lines were maintained in Dulbecco's modified Eagle medium with high $(25 \mathrm{~mm})$ glucose concentration, containing $1 \%$ glutamine, $1 \%$ pyruvate and $10 \%$ fetal bovine serum, $20 \mathrm{mg} / \mathrm{ml}$ gentamicin (Sigma-Aldrich, St Louis, MO, USA, $50 \mathrm{mg} / \mathrm{ml}$ ) at $37^{\circ}$ $\mathrm{C}$ in a humidified atmosphere of $5 \% \mathrm{CO}_{2}$. These cells were switched from high to LG $(5 \mathrm{~mm})$ for more than one month before experiments, forming two groups indicated as LG and HG. These conditions are indicated in the figures and legends.

\section{Population doubling time - (PDT assay)}

PDT is the time by which cell population doubles in number. MC38 cells were harvested at $90 \%$ confluence and counted. After plating the constant number of cells ( $10^{3}$ cells) to a cell culture dish $\mathrm{w} / 2 \mathrm{~mm}$ grid (Nalge Nunc International, New York, NY, USA), cells were counted at daily interval for 5 days. Doubling time was calculated based on the log phase of the 
growth curve acquired by the counting of the cells according to ${ }^{93}$, using the formula:

$$
\text { Doubling time }=\frac{\text { Total duration } * \ln (2)}{\ln (\mathrm{cf})-\ln (\mathrm{ci})}
$$

where 'cf' is the final cell concentration and 'ci' is the initial cell concentration. For total duration, any unit of time can be used and doubling time unit will be the same.

\section{Cell invasion assay}

Transwell membranes (polycarbonic membrane, diameter $6.5 \mathrm{~mm}$, pore size $8 \mu \mathrm{m}$-Costar, Cambridge, NY, USA) were coated with matrigel in a total of $100 \mu \mathrm{l}$ each transwell overnight in a full functioning laminar flow cabinet to let the matrigel solidify (matrigel: $0.375 \mathrm{mg} / \mathrm{ml}$ ). Afterwards, $2 \times 10^{5}$ MC38-GFP cells were seeded in $200 \mu \mathrm{l}$ of DMEM-free serum onto the upper chamber, and $900 \mu \mathrm{l}$ medium with $10 \%$ fetal calf serum was added to the lower chamber. After $24 \mathrm{~h}$ of incubation, cells adhering to the upper surface of the membrane were removed with a cotton swab. The migrated cells, which adhered to the lower surface, were fixed with $4 \%$ paraformaldehyde, and the number of cells attached to the lower surface was counted in the microscopy at $\times 10$ magnification. ${ }^{94}$ Data were obtained from three independent experiments.

\section{RNA isolation and RT-qPCR}

The samples were subjected to phenol-chloroform protocol for total RNA extraction using the TRIzol Reagent (Invitrogen, Carlsbad, CA, USA) according to the manufacturer's instructions, and RNA concentration was determined using a Nanodrop ND-1000 (Thermo Scientific, Wilmington, NC, USA). The RNA integrity was assessed by native agarose gel electrophoresis. RNA $(1 \mu \mathrm{g})$ was treated with RNAse-free DNase I (Fermentas International, Burlington, Canada) to eliminate genomic contamination, and used as template for CDNA synthesis using the High-Capacity cDNA Reverse Transcription Kit (Applied Biosystems, Foster City, CA, USA).

Primers for qPCR were designed using the Primer3 software. ${ }^{95}$ qPCR was performed in a StepOne real-time PCR System (Applied Biosystems) using the SYBR Green PCR Master Mix (Applied Biosystems) under the following conditions: one cycle for $10 \mathrm{~min}$ at $95^{\circ} \mathrm{C}$, followed by 40 cycles of $15 \mathrm{~s}$ at $95^{\circ} \mathrm{C}$ and $45 \mathrm{~s}$ at $60^{\circ} \mathrm{C}$. qPCR amplification was performed using specific primers for the target genes. All assays were run in triplicate, with HsGAPDH used as endogenous normalization control. Template controls were run in all $\mathrm{QPCR}$ experiments to verify whether reaction mixtures were contaminated with exogenous DNA. Reverse-transcriptase controls were also done to confirm that DNasel treatment had degraded any genomic DNA possibly contaminating RNA samples, and there was no genomic DNA amplification. In this condition, $C_{t}$ (cycle threshold) values for all analyzed genes were the same as in no template controls. In the statistical analysis of the qPCR results, the relative expression and ${ }^{{ }^{\Delta}}{ } C_{\mathrm{t}}$ values were calculated from obtained $C_{t}$ values, as described elsewhere. ${ }^{96}$ The ${ }^{\Delta \Delta} C_{t}$ mean values obtained from the experiments were submitted to Grubb's test to detect outliers $^{97}$, and the comparison among different conditions was made using Student's $t$-test and differences were considered significant at $P<0.05$. The relative expression values $\left(2^{-\Delta \Delta} C_{t}\right)$ were used only for graph construction. Statistical analysis was performed using the SAS software version 9.1.3 (SAS Institute, Cary, NC, USA).

\section{Lentivirus construction and transduction of MC38 cells}

Lentivirus particles were produced with PGFP-C-shScrambled or shGFPT1 plasmid (Origene, TL511601) and lentivirus packaging plasmids (Invitrogen) according to manufacturers' instructions.

\section{Flow cytometry}

The cell lectin binding was performed as described. ${ }^{11}$ For O-GlcNAc immunolabeling, $1 \times 10^{6}$ MC38 cells were fixed with $3.7 \%$ formaldehyde (Merck, Darmstadt, FRG) in phosphate-buffered saline (PBS) for $15 \mathrm{~min}$ at $4{ }^{\circ} \mathrm{C}$. Cells were pelleted by centrifugation at $300 \mathrm{~g}$ for $5 \mathrm{~min}$, permeabilized for $15 \mathrm{~min}$ with $0.2 \% \mathrm{v} / \mathrm{v}$ Tween 20 (Sigma) in PBS at $37^{\circ} \mathrm{C}$, and washed once with PBS. Permeabilized cells were incubated overnight at $4{ }^{\circ} \mathrm{C}$ with a 1:100 dilution of anti-O-GlcNAC antibody (RL2; SC59624, Santa Cruz Biotechnology, Dallas, TX, USA) in PBS ( $100 \mu$ l final volume). Cells were washed twice and followed by incubation at $4{ }^{\circ} \mathrm{C}$ for $2 \mathrm{~h}$ in $100 \mu \mathrm{l}$ of a 1:2500 dilution of Alexa Fluor 488-conjgated antibody (A-11001,
Invitrogen) in PBS. Final cell pellets were washed twice and suspended in PBS for flow cytometric acquisition of 10000 events with a FACSCalibur flow cytometer (BD Biosciences, San Jose, CA, USA). ${ }^{98}$ The fluorescence intensity data were analyzed with FlowJo $X$.

\section{Animals}

Experiments were performed on adult male C57BL/6 (3-4 months old) in accordance with the National Institutes of Health Guide for the Care and Use of Laboratory Animals (NIH Publication no. 80-23), and were approved by the Committee for the Use of Experimental Animals of our institution. Animals were selected using a simple random method. Hyperglycemic mice were induced with a single intra-peritoneal (i.p.) injection of $150 \mathrm{mg} / \mathrm{kg}$ STZ (Sigma-Aldrich) diluted with $0.1 \mathrm{~m}$ sodium citrate buffer $(\mathrm{pH} 4.3)$ prior to use. Control mice received $0.1 \mathrm{~m}$ sodium citrate buffer $(\mathrm{pH}$ 4.3) in a single i.p. injection as vehicle. Blood was collected weekly from tail veins, and blood glucose levels were measured using a validated onetouch basic glucose measurement system (Accu-chek Active Test meter, Roche) and body weight was also measured weekly from baseline (Supplementary Figures $1 \mathrm{~A}, \mathrm{~B}$ ). Seven days after STZ treatment, the mice with blood glucose concentrations $>300 \mathrm{mg} / \mathrm{dl}$ received cell infusion. No blinding investigator was used in the animals' experiments.

\section{Tumor growth assay}

Subcutaneous tumor was induced by implantation of $1 \times 10^{5}$ MC 38 cells on the right flank of C57BL/6. Animals were separated into the following six experimental groups: (1) mice injected with cells cultured in LG condition (MC38-LG); (2) mice injected with cells cultured in HG condition (MC38-HG); (3) hyperglycemic mice injected with cells cultured in HG condition (MC38-HG-HyG); (4) mice injected with cells cultured in HG condition and pre-treated with DON (MC38-HG-DON); (5) mice injected with cells cultured in HG condition and silenced to GFAT1 (MC38-HGshGAT); and (6) mice injected with cells cultured in HG condition and scrambled to GFAT1 (MC38-HG-shGAT). The tumor was measured twice a week for 28 days, and tumor area was calculated. Growth curves for tumors were plotted as the mean area \pm s.e.m. of tumors of mice from each group. No statistical method was used to predict sample size and size of the sample varied from 9 to 18 per group, specified in each figure's legends.

\section{Experimental lung metastasis}

As an animal model of lung metastasis, $2 \times 10^{5} \mathrm{MC} 38$ cells were inoculated in $100 \mu \mathrm{l}$ of DMEM via tail vein of the mice. After 22 days, mice were anaesthetized with an i.p injection of Ketamine/xylazine $100 \mathrm{mg} / \mathrm{kg}$ and $10 \mathrm{mg} / \mathrm{kg}$ body weight, respectively, and transcardially perfused with PBS. A picture of dissected lungs was taken and a GFP fluorescence image was obtained in IVIS Lumina System. Further, lungs were processed for quantification of metastasis by detection of GFP fluorescence. Perfused lungs were homogenized in $2 \mathrm{ml}$ of a hypotonic buffer $(20 \mathrm{~mm}$ Tris-Cl, $\mathrm{pH} 7.0$ ) by using a potter. Triton $\mathrm{X}-100$ was added to a final concentration of $0,5 \%$. After $30 \mathrm{~min}$ on ice, the insoluble debris was spun down $(10000 \mathrm{~g}$ for $10 \mathrm{~min}$ ), $10 \mu \mathrm{l}$ of each supernatant was diluted with Tris-Cl buffer (20 mm Tris-Cl, pH 7.0) to a final volume of $100 \mu \mathrm{l}$, and transferred to a quartz cubet. Fluorescence was read on a Varian Cary Eclipse (Varian) at Ex 485 and Em 508. Background levels for subtraction were determined on lungs from mice, which had not been injected with GFP-labeled cells. ${ }^{92}$

Tissue lysates and western blot

Total lysates were obtained homogenizing tissue samples in a potter with lysis buffer $1 \%$ Triton X-100, $0.5 \%$ sodium deoxycolate, $0.2 \%$ SDS, $150 \mathrm{~mm}$ $\mathrm{NaCl}, 2 \mathrm{~mm}$ EDTA, $10 \mathrm{~mm}$ HEPES (pH 7.4), $20 \mathrm{~mm} \mathrm{NaF}, 1 \mathrm{~mm}$ orthovanadate and a protease inhibitor cocktail, for $30 \mathrm{~min}$ at $4{ }^{\circ} \mathrm{C}$. After centrifugation at $10000 \mathrm{~g}$ for $10 \mathrm{~min}$ at $4{ }^{\circ} \mathrm{C}$, the supernatant was removed and stored at $-80^{\circ} \mathrm{C}$. For immunoblotting equal amounts of protein $(30 \mu \mathrm{g} / \mathrm{lane})$ from tissue lysates were separated on $7.5 \%$ SDS-PAGE and transferred onto nitrocellulose sheets. The membranes were blocked and incubated overnight with primary antibodies GFAT1 and GFAT2 (SC134894 and SC134710, respectively, Santa Cruz Biotechnology), CTD-110.6 for O-GlcNAC (SC-59623, Santa Cruz Biotechnology), $\beta$-actin (A5316, Sigma Chemical) and vinculin (V4505, Sigma Chemical). After washing, the membranes were incubated for $1 \mathrm{~h}$ with peroxidase-conjugated secondary antibodies, developed using ECL (GE Healthcare, Pittsburgh, PA, USA) and exposed to Image Quant LAS 4000 (GE Healthcare). ImageJ software was 
used for densitometry analysis of immunoblots, and measurements were normalized against $\beta$-actin or vinculin loading controls.

\section{Lectin binding in tissue sections}

Animals were deeply anesthetized with an intraperitoneal injection of Ketamine/xylazine $100 \mathrm{mg} / \mathrm{kg}$ and $10 \mathrm{mg} / \mathrm{kg}$ body weight, respectively, and were transcardially perfused with $4 \%$ paraformaldehyde in $0.1 \mathrm{~m}$ PBS, $\mathrm{pH}$ 7.4. Tissue was cryoprotected in $30 \%$ sucrose in $0.1 \mathrm{M} \mathrm{TPO}_{4}$ for at least 1 week, then embedded in O.T.C compound (Meio Tissue-Tek, Sakura) and cryosectioned into $20-\mu \mathrm{m}$ sections. Lectins and their nominal sugar specificities are listed in Supplementary Table 1. Staining was performed at $4{ }^{\circ} \mathrm{C}$ overnight to $100 \mu \mathrm{g} / \mathrm{ml}$. Negative controls consisted of streptavidin alone and biotinylated lectins without fluorescent streptavidin. Fluorescent samples were analyzed under a confocal microscope (Zeiss LSM 510 Meta).

\section{Dot blot}

For dot blot analysis, $10 \mu \mathrm{g}$ of total cell lysates were spotted and immobilized in nitrocellulose membrane. The membrane was blocked with $3 \%$ of bovine serum albumin (BSA) and incubated overnight with biotinilated Sambucus nigraLectin (SNA, Vector Laboratories), a2-6-Neu5Ac labeling. The blots were then washed, incubated with Extravidinperoxidase (Sigma), developed using ECL (GE Healthcare) and exposed to Image Quant LAS 4000 (GE Healthcare). ImageJ software was used for densitometric analysis, and measurements were normalized against Ponceau staining.

\section{Magnetic resonance imaging}

The initial development of subcutaneous tumor was analyzed in vivo by magnetic resonance imaging measurements 5 days after MC38 cells injection. The animals were anesthetized with Isoforine and received an intravenous injection $(0.5 \mathrm{ml} / \mathrm{kg}$ weight body) with the contrast agent gadolinium (Dotarem; $0.5 \mathrm{mmol} / \mathrm{ml}$ ). Images were acquired with a 7T magnetic resonance scanner (Varian MRI System 7T/210 ASR Horizontal Bore Magnet, Agilent Technologies, Santa Clara, CA, USA). Three T1-weighted spin echo sequences were acquired (axial with $\mathrm{TR} / \mathrm{TE}=420 \mathrm{~ms} / 15 \mathrm{~ms}$, matrix $=128 \times 128, \mathrm{FOV}=80 \mathrm{~mm} / 50 \mathrm{~mm}, 20$ slices, no gap, thickness $=1 \mathrm{~mm}, \mathrm{NEX}=10$; coronal with $\mathrm{TR} / \mathrm{TE}=750 \mathrm{~ms} / 15 \mathrm{~ms}$, matrix $=128 \times 128, \quad F O V=35 \mathrm{~mm} / 35 \mathrm{~mm}, \quad 35$ slices, no gap, thickness $=1 \mathrm{~mm}$, NEX $=10$; sagittal with $T R / T E=525 \mathrm{~ms} / 15 \mathrm{~ms}$, matrix $=128 \times 128, \quad F O V=80 \mathrm{~mm} / 40 \mathrm{~mm}, 25$ slices, no gap, thickness $=1 \mathrm{~mm}, \mathrm{NEX}=10$ ) and a T2-wieghted fast spin echo sequence (TR/ TE $=2520 \mathrm{~ms} / 15 \mathrm{~ms}$, matrix $=128 \times 128, \quad F O V=80 \mathrm{~mm} / 50 \mathrm{~mm}, 20$ slices, no gap, thickness $=1 \mathrm{~mm}, \mathrm{NEX}=10$ )

\section{UDP-hexosamines detection}

UDP-hexosamines produced by MC38 cells in vitro were determined by HPLC using a Hypercarb PGC column $(3.0 \mathrm{~mm} \times 150 \mathrm{~mm}$, Thermo Scientific) as described before ${ }^{20}$.

The presence of UDP-hexosamines on-tissue samples was revealed by high-resolution matrix-assisted laser desorption/ionization Fouriertransform ion cyclotron resonance mass spectrometry imaging (MALDIFT-ICR MSI). Subcutaneous tumor from euglycemic and hyperglycemic mice were frozen in liquid nitrogen and stored at $-80^{\circ} \mathrm{C}$. Frozen $(12 \mu \mathrm{m})$ sections were mounted onto indium-tin-oxide (ITO)-coated glass slides (Bruker Daltonik, Bremen, Germany) pretreated with 1:1 poly-L-lysine (Sigma Aldrich, Munich, Germany) and 0.1\% Nonidet P-40 (Sigma) for MSI analysis. Adjacent sections were mounted on glass slides for hematoxylin and eosin (H\&E) staining. All sections were stored at $-80^{\circ} \mathrm{C}$ until analysis. Prior to matrix application, tumor sections were dehydrated in a vacuum for $1 \mathrm{~h}$ at room temperature. Samples were coated in $10 \mathrm{mg} / \mathrm{ml}$ 9-aminoacridine matrix in $70 \%$ methanol using an ImagePrep spray roboter (Bruker Daltonics, Billerica, MA, USA). MSI was performed in negative ion mode on a Bruker Solarix 7 T FT-ICR MS (Bruker), over a mass range of $\mathrm{m} / \mathrm{z} 150-1000$ and $50 \mu \mathrm{m}$ lateral resolution. All measurements included a non-tissue measurement region as a background control. Acquired data were analyzed using SCILS Lab (Bruker Daltonics) and normalized against the root mean square of all data points. MS/MS was conducted on On-tissue samples using electron capture dissociation in the collision cell.
Patient samples

Colon adenocarcinoma and adjacent normal tissues derived from biopsy of seven patients (four males and three females) were obtained from the Instituto Nacional de Câncer (INCA), Rio de Janeiro, Brazil, which banked samples following patient consent. All samples were from surgical resections and were evaluated by a board-certified pathologist. In all cases, control specimens were collected from the accompanying normal mucosa, distant approximately $10 \mathrm{~cm}$ from the carcinoma. The cancer tissue and the normal epithelial layer were carefully isolated from the resected colon with scissors and forceps. All tumor samples used were determined to be $>80 \%$ tumor by evaluation of H\&E-stained sections. H\&E-stained sections of each normal sample were evaluated and determined to lack any precancerous lesions. Clinic pathologic features are listed in Supplementary Table 2. Samples for immunoblotting were frozen at $-80^{\circ} \mathrm{C}$ and those used for QRT-PCR were immediately immersed in RNA later stabilization solution (Ambion-Life Technologies, Carlsbad, CA, USA) and stored at $4{ }^{\circ} \mathrm{C}$ overnight, then samples were moved to $-80^{\circ} \mathrm{C}$ for long-term storage. This study was carried out with approval of the Brazilian National Cancer Institute's Ethic Committee (Registration number: 84/04).

\section{Statistical analysis}

All data were analyzed in Prism (Graphpad). One/two-tail unpaired $t$-test or one/two-way ANOVA (Dunnett, Tukey's/Bonferroni post test) was used when comparing two groups or more than two groups, respectively. Error bars represent mean \pm s.e.m. when not specified.

\section{Study approval}

All experiments involving mice were approved by the Institutional Animal Care and Use Committee and followed all state and federal rules and regulations. All human samples used in experiments were deidentified and obtained from the Instituto Nacional do Cancer, which banked samples following informed consent.

\section{CONFLICT OF INTEREST}

The authors declare no conflict of interest.

\section{ACKNOWLEDGEMENTS}

We are grateful to the Centro Nacional de Biologia Estrutural e Bioimagem (CENABIO), to Centro de Espectrometria de Massas de Biomoléculas (CEMBIO) (Rio de Janeiro, Brazil) and Plataforma de Imuno-análise (PIA). This work was supported by grants from Conselho Nacional de Desenvolvimento Científico e Tecnológico (CNPq), Fundação Carlos Chagas Filho de Amparo à Pesquisa do Estado do Rio de Janeiro (FAPERJ), and Coordenação de Aperfeiçoamento de Pessoal de Nível Superior (CAPES).

\section{AUTHOR CONTRIBUTIONS}

AVS participated in the design, conducted in vitro and in vivo experiments, analyzed the data and wrote the manuscript. HFL performed in vitro experiments. NM participated in in vivo experiments; IO, IFP and KCG conducted experiments of human samples. JFJ and JAMD provided total cell lysate and CDNA from human samples. LT conducted the construct of shGFAT. NH conducted HPLC analysis. RMB conducted the MS experiments. WBD assisted in experimental design, obtained funding for the study and edited the manuscript. AT designed the experiments, obtained funding for the study and wrote the manuscript.

\section{REFERENCES}

1 Siegel R, Desantis C, Jemal A. Colorectal cancer statistics, 2014. CA Cancer J Clin 2014; 64: 104-117.

2 Giovannucci E, Harlan DM, Archer MC, Bergenstal RM, Gapstur SM, Habel LA et al. Diabetes and cancer: a consensus report. CA Cancer J Clin 2010; 60: 207-221.

3 Vigneri P, Frasca F, Sciacca L, Pandini G, Vigneri R. Diabetes and cancer. Endocr Relat Cancer 2009; 16: 1103-1123.

4 Johnson JA, Carstensen B, Witte D, Bowker SL, Lipscombe L, Renehan AG et al. Diabetes and cancer (1): evaluating the temporal relationship between type 2 diabetes and cancer incidence. Diabetologia 2012; 55: 1607-1618. 
5 Suh S, Kim KW. Diabetes and cancer: is diabetes causally related to cancer? Diabetes Metab J 2011; 35: 193-198.

6 Barone BB, Yeh HC, Snyder CF, Peairs KS, Stein KB, Derr RL et al. Long-term all-cause mortality in cancer patients with preexisting diabetes mellitus: a systematic review and meta-analysis. J Am Med Assoc 2008; 300: 2754-2764.

7 Mills KT, Bellows CF, Hoffman AE, Kelly TN, Gagliardi G. Diabetes mellitus and colorectal cancer prognosis: a meta-analysis. Dis Colon Rectum 2013; 56: 1304-1319.

8 Giouleme O, Diamantidis MD, Katsaros MG. Is diabetes a causal agent for colorectal cancer? Pathophysiological and molecular mechanisms. World J Gastroenterol 2011; 17: 444-448.

9 Mills KT, Bellows CF, Hoffman AE, Kelly TN, Gagliardi G. Diabetes mellitus and colorectal cancer prognosis: a meta-analysis. Dis Colon Rectum 2013; 56: 1304-1319.

10 Duan WX, Shen X, Lei JJ, Xu QH, Yu YT, Li R et al. Hyperglycemia, a neglected factor during cancer progression. BioMed Res Int 2014; 2014: 461917.

11 Alisson-Silva F, Freire-de-Lima L, Donadio JL, Lucena MC, Penha L, Sa-Diniz JN et al. Increase of O-glycosylated oncofetal fibronectin in high glucose-induced epithelial-mesenchymal transition of cultured human epithelial cells. PLOS ONE 2013; 8: e60471.

12 Rajaram S, Baylink DJ, Mohan S. Insulin-like growth factor-binding proteins in serum and other biological fluids: regulation and functions. Endocr Rev 1997; 18: 801-831.

13 Devaraj S, Venugopal SK, Singh U, Jialal I. Hyperglycemia induces monocytic release of interleukin- 6 via induction of protein kinase c-\{alpha\} and -\{beta\}. Diabetes 2005; 54: 85-91.

14 Gonzalez Y, Herrera MT, Soldevila G, Garcia-Garcia L, Fabian G, Perez-Armendariz EM et al. High glucose concentrations induce TNF-alpha production through the down-regulation of $\mathrm{CD} 33$ in primary human monocytes. BMC Immunol 2012; 13: 19.

15 Lopez R, Arumugam A, Joseph R, Monga K, Boopalan T, Agullo P et al. Hyperglycemia enhances the proliferation of non-tumorigenic and malignant mammary epithelial cells through increased leptin/IGF1R signaling and activation of AKT/mTOR. PLoS ONE 2013; 8: e79708.

16 Garcia-Jimenez C, Garcia-Martinez JM, Chocarro-Calvo A, De la Vieja A. A new link between diabetes and cancer: enhanced WNT/beta-catenin signaling by high glucose. J Mol Endocrinol 2014; 52: R51-R66.

17 Almuhaideb A, Papathanasiou N, Bomanji J. 18F-FDG PET/CT imaging in oncology. Ann Saudi Med 2011; 31: 3-13.

18 Pavlova NN, Thompson CB. The emerging hallmarks of cancer metabolism. Cell Metab 2016; 23: 27-47.

19 Marshall S, Bacote V, Traxinger RR. Discovery of a metabolic pathway mediating glucose-induced desensitization of the glucose transport system. Role of hexosamine biosynthesis in the induction of insulin resistance. J Biol Chem 1991; 266: 4706-4712.

20 Lucena MC, Carvalho-Cruz P, Donadio JL, Oliveira IA, de Queiroz RM, Marinho-Carvalho MM et al. Epithelial mesenchymal transition induces aberrant glycosylation through hexosamine biosynthetic pathway activation. J Biol Chem 2016; 291: 12917-12929.

21 Vasconcelos-Dos-Santos A, Oliveira IA, Lucena MC, Mantuano NR, Whelan SA, Dias WB et al. Biosynthetic machinery involved in aberrant glycosylation: promising targets for developing of drugs against cancer. Front Oncol 2015; 5: 138.

22 Oki T, Yamazaki K, Kuromitsu J, Okada M, Tanaka I. cDNA cloning and mapping of a novel subtype of glutamine:fructose-6-phosphate amidotransferase (GFAT2) in human and mouse. Genomics 1999; 57: 227-234.

23 Srinivasan V, Sandhya N, Sampathkumar R, Farooq S, Mohan V, Balasubramanyam M. Glutamine fructose-6-phosphate amidotransferase (GFAT) gene expression and activity in patients with type 2 diabetes: inter-relationships with hyperglycaemia and oxidative stress. Clin Biochem 2007; 40: 952-957.

24 Zhang W, Liu J, Tian L, Liu Q, Fu Y, Garvey WT. TRIB3 mediates glucose-induced insulin resistance via a mechanism that requires the hexosamine biosynthetic pathway. Diabetes 2013; 62: 4192-4200.

25 Heimburg-Molinaro J, Lum M, Vijay G, Jain M, Almogren A, Rittenhouse-Olson K. Cancer vaccines and carbohydrate epitopes. Vaccine 2011; 29: 8802-8826.

26 Holst S, Wuhrer M, Rombouts Y. Glycosylation characteristics of colorectal cancer. Adv Cancer Res 2015; 126: 203-256.

27 Guo H, Nagy T, Pierce M. Post-translational glycoprotein modifications regulate colon cancer stem cells and colon adenoma progression in $\mathrm{Apc}(\mathrm{min} /+)$ mice through altered Wnt receptor signaling. J Biol Chem 2014; 289: 31534-31549.

28 Pinho SS, Reis CA. Glycosylation in cancer: mechanisms and clinical implications. Nat Rev Cancer 2015; 15: 540-555.

29 Buck A, Ly A, Balluff B, Sun N, Gorzolka K, Feuchtinger A et al. High-resolution MALDI-FT-ICR MS imaging for the analysis of metabolites from formalin-fixed, paraffin-embedded clinical tissue samples. J Pathol 2015; 237: 123-132.
30 Mascini NE, Cheng M, Jiang L, Rizwan A, Podmore $H$, Bhandari DR et al. Mass spectrometry imaging of the hypoxia marker pimonidazole in a breast tumor model. Anal Chem 2016; 88: 3107-3114.

31 Hart GW, Housley MP, Slawson C. Cycling of O-linked beta-N-acetylglucosamine on nucleocytoplasmic proteins. Nature 2007; 446: 1017-1022.

32 Duan W, Shen X, Lei J, Xu Q, Yu Y, Li R et al. Hyperglycemia, a neglected factor during cancer progression. BioMed Res Int 2014; 2014: 461917.

33 Wojciechowska J, Krajewski W, Bolanowski M, Krecicki T, Zatonski T. Diabetes and cancer: a review of current knowledge. Exp Clin Endocrinol Diabetes 2016; 124: 263-275.

34 Harris RD, Steffes MW, Bilous RW, Sutherland DE, Mauer SM. Global glomerular sclerosis and glomerular arteriolar hyalinosis in insulin dependent diabetes. Kidney Int 1991; 40: 107-114.

35 Heilig CW, Concepcion LA, Riser BL, Freytag SO, Zhu M, Cortes P. Overexpression of glucose transporters in rat mesangial cells cultured in a normal glucose milieu mimics the diabetic phenotype. J Clin Invest 1995; 96: 1802-1814.

36 Saengboonmee C, Seubwai W, Pairojkul C, Wongkham S. High glucose enhances progression of cholangiocarcinoma cells via STAT3 activation. Sci Rep 2016; 6: 18995

37 Masur K, Vetter C, Hinz A, Tomas N, Henrich H, Niggemann B et al. Diabetogenic glucose and insulin concentrations modulate transcriptome and protein levels involved in tumour cell migration, adhesion and proliferation. $\mathrm{Br} J$ Cancer 2011; 104: $345-352$.

38 Onodera Y, Nam JM, Bissell MJ. Increased sugar uptake promotes oncogenesis via EPAC/RAP1 and O-GICNAc pathways. J Clin Invest 2014; 124: 367-384.

39 Lin $\mathrm{CY}$, Lee $\mathrm{CH}$, Huang CC, Lee ST, Guo HR, Su SB. Impact of high glucose on metastasis of colon cancer cells. World J Gastroenterol 2015; 21: 2047-2057.

40 Jiang X, Ma N, Wang D, Li F, He R, Li D et al. Metformin inhibits tumor growth by regulating multiple miRNAs in human cholangiocarcinoma. Oncotarget 2015; 6: 3178-3194.

41 Li W, Ma Q, Liu J, Han L, Ma G, Liu H et al. Hyperglycemia as a mechanism of pancreatic cancer metastasis. Front Biosci (Landmark Ed) 2012; 17: 1761-1774.

42 Krechler T, Novotny J, Zeman M, Krska Z, Svestka T, Svab J et al. Pancreatic carcinoma and diabetes mellitus. Casopis Lekaru Ceskych 2004; 143: 97-100.

43 Libby G, Donnelly LA, Donnan PT, Alessi DR, Morris AD, Evans JM. New users of metformin are at low risk of incident cancer: a cohort study among people with type 2 diabetes. Diabetes Care 2009; 32: 1620-1625.

44 Liu B, Fan Z, Edgerton SM, Deng XS, Alimova IN, Lind SE et al. Metformin induces unique biological and molecular responses in triple negative breast cancer cells. Cell Cycle 2009; 8: 2031-2040.

45 Algire C, Amrein L, Zakikhani M, Panasci L, Pollak M. Metformin blocks the stimulative effect of a high-energy diet on colon carcinoma growth in vivo and is associated with reduced expression of fatty acid synthase. Endocr Relat Cancer 2010: 17: 351-360.

46 Buzzai M, Jones RG, Amaravadi RK, Lum JJ, DeBerardinis RJ, Zhao F et al. Systemic treatment with the antidiabetic drug metformin selectively impairs p53-deficient tumor cell growth. Cancer Res 2007; 67: 6745-6752.

47 Zhang ZJ, Zheng ZJ, Kan H, Song Y, Cui W, Zhao G et al. Reduced risk of colorectal cancer with metformin therapy in patients with type 2 diabetes: a meta-analysis. Diabetes Care 2011; 34: 2323-2328.

48 Ryu TY, Park J, Scherer PE. Hyperglycemia as a risk factor for cancer progression. Diabetes Metab J 2014; 38: 330-336.

49 Hahn T, Barth S, Hofmann W, Reich O, Lang I, Desoye G. Hyperglycemia regulates the glucose-transport system of clonal choriocarcinoma cells in vitro. A potential molecular mechanism contributing to the adjunct effect of glucose in tumor therapy. Int J Cancer 1998; 78: 353-360.

50 Amoedo ND, Valencia JP, Rodrigues MF, Galina A, Rumjanek FD. How does the metabolism of tumour cells differ from that of normal cells. Biosci Rep 2013; 33.

51 Aurer I, Lauc G, Dumic J, Rendic D, Matisic D, Milos M et al. Aberrant glycosylation of lgg heavy chain in multiple myeloma. Coll Antropol 2007; 31: 247-251.

52 Qiu Y, Patwa TH, Xu L, Shedden K, Misek DE, Tuck M et al. Plasma glycoprotein profiling for colorectal cancer biomarker identification by lectin glycoarray and lectin blot. J Proteome Res 2008; 7: 1693-1703.

53 Vavasseur F, Dole K, Yang J, Matta KL, Myerscough N, Corfield A et al. O-glycan biosynthesis in human colorectal adenoma cells during progression to cancer. Eur J Biochem 1994; 222: 415-424.

54 Holst S, Stavenhagen K, Balog Cl, Koeleman CA, McDonnell LM, Mayboroda OA et al. Investigations on aberrant glycosylation of glycosphingolipids in colorectal cancer tissues using liquid chromatography and matrix-assisted laser desorption time-of-flight mass spectrometry (MALDI-TOF-MS). Mol Cell Proteomics 2013; 12: 3081-3093.

55 Baumann H, Nudelman E, Watanabe K, Hakomori S. Neutral fucolipids and fucogangliosides of rat hepatoma HTC and H35 cells, rat liver, and hepatocytes. Cancer Res 1979; 39: 2637-2643. 
56 Liu J, Yang L, Jin M, Xu L, Wu S. Regulation of the invasion and metastasis of human glioma cells by polypeptide $\mathrm{N}$-acetylgalactosaminyltransferase 2 . Mol Med Rep 2011; 4: 1299-1305.

57 Guo JM, Chen HL, Wang GM, Zhang YK, Narimatsu H. Expression of UDP-GalNAC: polypeptide $\mathrm{N}$-acetylgalactosaminyltransferase-12 in gastric and colonic cancer cell lines and in human colorectal cancer. Oncology 2004; 67: 271-276.

58 Ding MX, Wang HF, Wang JS, Zhan H, Zuo YG, Yang DL et al. ppGalNAc T1 as a potential novel marker for human bladder cancer. Asian Pac J Cancer Prev 2012; 13: $5653-5657$.

59 Onitsuka K, Shibao K, Nakayama Y, Minagawa N, Hirata K, Izumi H et al. Prognostic significance of UDP-N-acetyl-alpha-D-galactosamine:polypeptide $\mathrm{N}$-acetylgalactosaminyltransferase-3 (GalNAc-T3) expression in patients with gastric carcinoma. Cancer Sci 2003; 94: 32-36.

60 Moriwaki K, Miyoshi E. Fucosylation and gastrointestinal cancer. World J Hepatol 2010; 2: 151-161.

61 Moriwaki K, Noda K, Furukawa Y, Ohshima K, Uchiyama A, Nakagawa T et al. Deficiency of GMDS leads to escape from NK cell-mediated tumor surveillance through modulation of TRAIL signaling. Gastroenterology 2009. 137 1: 198.e1-2.

62 de-Freitas-Junior JC, Morgado-Diaz JA. The role of N-glycans in colorectal cancer progression: potential biomarkers and therapeutic applications. Oncotarget 2015; 7: 19395-19413.

63 Nakayama K, Moriwaki K, Imai T, Shinzaki S, Kamada Y, Murata K et al. Mutation of GDP-mannose-4,6-dehydratase in colorectal cancer metastasis. PLoS ONE 2013; 8: e70298.

64 Kemmner W, Roefzaad C, Haensch W, Schlag PM. Glycosyltransferase expression in human colonic tissue examined by oligonucleotide arrays. Biochim Biophys Acta 2003; 1621: 272-279.

65 Giuffre G, Vitarelli E, Tuccari G, Ponz de Leon M, Barresi G. Detection of Tn sialosyl-Tn and T antigens in hereditary nonpolyposis colorectal cancer. Virchows Arc 1996; 429: 345-352.

66 Itzkowitz SH, Yuan M, Montgomery CK, Kjeldsen T, Takahashi HK, Bigbee WL et al. Expression of Tn, sialosyl-Tn, and T antigens in human colon cancer. Cancer Res 1989; 49: 197-204.

67 Park JJ, Lee M. Increasing the alpha 2, 6 sialylation of glycoproteins may contribute to metastatic spread and therapeutic resistance in colorectal cancer. Gut Liver 2013; 7: 629-641.

68 Swindall AF, Londono-Joshi Al, Schultz MJ, Fineberg N, Buchsbaum DJ, Bellis SL. ST6Gal-I protein expression is upregulated in human epithelial tumors and correlates with stem cell markers in normal tissues and colon cancer cell lines. Cancer Res 2013; 73: 2368-2378.

69 Seales EC, Jurado GA, Brunson BA, Wakefield JK, Frost AR, Bellis SL. Hypersialylation of beta1 integrins, observed in colon adenocarcinoma, may contribute to cancer progression by up-regulating cell motility. Cancer Res 2005; 65: 4645-4652.

70 Sethi MK, Thaysen-Andersen M, Smith JT, Baker MS, Packer NH, Hancock WS et al. Comparative $\mathrm{N}$-glycan profiling of colorectal cancer cell lines reveals unique bisecting GlcNAc and alpha-2,3-linked sialic acid determinants are associated with membrane proteins of the more metastatic/aggressive cell lines. J Proteome Res 2014; 13: 277-288.

71 Berg EL, Robinson MK, Mansson O, Butcher EC, Magnani JL. A carbohydrate domain common to both sialyl $\operatorname{Le}(a)$ and sialyl $\operatorname{Le}(X)$ is recognized by the endothelial cell leukocyte adhesion molecule ELAM-1. J Biol Chem 1991; 266: 14869-14872.

72 Liu FT, Rabinovich GA. Galectins as modulators of tumour progression. Nat Rev Cancer 2005; 5: 29-41.

73 Lau KS, Partridge EA, Grigorian A, Silvescu Cl, Reinhold VN, Demetriou M et al. Complex $\mathrm{N}$-glycan number and degree of branching cooperate to regulate cell proliferation and differentiation. Cell 2007; 129: 123-134.

74 Hirabayashi J, Hashidate T, Arata Y, Nishi N, Nakamura T, Hirashima M et al. Oligosaccharide specificity of galectins: a search by frontal affinity chromatography. Biochim Biophys Acta 2002; 1572: 232-254.

75 Wellen KE, Thompson CB. A two-way street: reciprocal regulation of metabolism and signalling. Nat Rev Mol Cell Biol 2012; 13: 270-276.

76 Dennis JW, Nabi IR, Demetriou M. Metabolism, cell surface organization, and disease. Cell 2009; 139: 1229-1241.

77 Zachara NE, Hart GW. O-GICNAc a sensor of cellular state: the role of nucleocytoplasmic glycosylation in modulating cellular function in response to nutrition and stress. Biochim Biophys Acta 2004; 1673: 13-28.

78 de Queiroz RM, Carvalho E, Dias WB. O-glcnacylation: the sweet side of the cancer. Front Oncol 2014; 4: 132.
79 Bennmann D, Weidemann W, Thate A, Kreuzmann D, Horstkorte R. Aberrant O-GIcNAcylation disrupts GNE enzyme activity in GNE myopathy. FEBS J 2016; 283: 2285-2294.

80 Hanover JA, Krause MW, Love DC. Bittersweet memories: linking metabolism to epigenetics through O-GlcNAcylation. Nat Rev Mol Cell Biol 2012; 13: 312-321.

81 Durning SP, Flanagan-Steet $\mathrm{H}$, Prasad N, Wells L. O-linked beta-Nacetylglucosamine (O-GIcNAc) acts as a glucose sensor to epigenetically regulate the insulin gene in pancreatic beta cells. J Biol Chem 2016; 291: 2107-2118.

82 Dehennaut V, Leprince D, Lefebvre T. O-GlcNAcylation, an epigenetic mark. Focus on the histone Code, TET family proteins, and polycomb group proteins. Front Endocrinol 2014; 5: 155.

83 Cencioni C, Spallotta F, Greco S, Martelli F, Zeiher AM, Gaetano C. Epigenetic mechanisms of hyperglycemic memory. Int J Biochem Cell Biol 2014; 51: 155-158.

84 Plass C, Pfister SM, Lindroth AM, Bogatyrova O, Claus R, Lichter P. Mutations in regulators of the epigenome and their connections to global chromatin patterns in cancer. Nat Rev Genet 2013; 14: 765-780.

85 Gupta C, Kaur J, Tikoo K. Regulation of MDA-MB-231 cell proliferation by GSK-3beta involves epigenetic modifications under high glucose conditions. Exp Cell Res 2014; 324: 75-83.

86 Vojta A, Samarzija I, Bockor L, Zoldos V. Glyco-genes change expression in cancer through aberrant methylation. Biochim Biophys Acta 2016; 1860: 1776-1785.

87 Saldova R, Dempsey E, Perez-Garay M, Marino K, Watson JA, Blanco-Fernandez A et al. 5-AZA-2'-deoxycytidine induced demethylation influences $\mathrm{N}$-glycosylation of secreted glycoproteins in ovarian cancer. Epigenetics 2011; 6: 1362-1372.

88 Greville G, McCann A, Rudd PM, Saldova R. Epigenetic regulation of glycosylation and the impact on chemo-resistance in breast and ovarian cancer. Epigenetics 2016; 11: 845-8570.

89 Kizuka Y, Kitazume S, Yoshida M, Taniguchi N. Brain-specific expression of $\mathrm{N}$-acetylglucosaminyltransferase IX (GnT-IX) is regulated by epigenetic histone modifications. J Biol Chem 2011; 286: 31875-31884.

90 Kizuka Y, Kitazume S, Okahara K, Villagra A, Sotomayor EM, Taniguchi N Epigenetic regulation of a brain-specific glycosyltransferase $\mathrm{N}$-acetylglucosaminyltransferase-IX (GnT-IX) by specific chromatin modifiers. J Biol Chem 2014; 289: 11253-11261.

91 Itkonen HM, Minner S, Guldvik IJ, Sandmann MJ, Tsourlakis MC, Berge V et al. O-GIcNAc transferase integrates metabolic pathways to regulate the stability of c-MYC in human prostate cancer cells. Cancer Res 2013; 73: 5277-5287.

92 Borsig L, Wong R, Hynes RO, Varki NM, Varki A. Synergistic effects of L- and P-selectin in facilitating tumor metastasis can involve non-mucin ligands and implicate leukocytes as enhancers of metastasis. Proc of the Natl Acad Sci USA 2002; 99: 2193-2198.

93 Ruth V. Available at: http://www.doubling-time.com/compute.php (2006) Accessed on 2016.

94 Tolboom TC, Huizinga TW. In vitro matrigel fibroblast invasion assay. Methods $\mathrm{Mol}$ Med 2007; 135: 413-421.

95 Rozen S, Skaletsky H. Primer3 on the WWW for general users and for biologist programmers. Methods Mol Biol 2000; 132: 365-386.

96 Nordgard O, Kvaloy JT, Farmen RK, Heikkila R. Error propagation in relative real-time reverse transcription polymerase chain reaction quantification models: the balance between accuracy and precision. Anal Biochem 2006; 356: 182-193.

97 Burns MJ, Nixon GJ, Foy CA, Harris N. Standardisation of data from real-time quantitative PCR methods-evaluation of outliers and comparison of calibration curves. BMC Biotechnol 2005; 5: 31.

98 Holmes K, Lantz LM, Fowlkes BJ, Schmid I, Giorgi JV. Preparation of cells and reagents for flow cytometry. In: John E Coligan et al. (eds). Current Protocols in Immunology, Chapter 5: Unit 5.3, 2001.

Oncogenesis is an open-access journal published by Nature Publishing Group. This work is licensed under a Creative Commons Attribution 4.0 International License. The images or other third party material in this article are included in the article's Creative Commons license, unless indicated otherwise in the credit line; if the material is not included under the Creative Commons license, users will need to obtain permission from the license holder to reproduce the material. To view a copy of this license, visit http://creativecommons.org/licenses/by/4.0/

(c) The Author(s) 2017

Supplementary Information accompanies this paper on the Oncogenesis website (http://www.nature.com/oncsis) 